\title{
Market Definition for Broadband Internet in Slovakia - Are Fixed and Mobile Technologies in the Same Market?*
}

\author{
Lukasz Grzybowski ${ }^{\dagger} \quad$ Rainer Nitsche ${ }^{\ddagger} \quad$ Frank Verboven ${ }^{\S} \quad$ Lars Wiethaus
}

February 20, 2014

\begin{abstract}
This paper uses a rich survey of 6,446 households in Slovakia to estimate price elasticities of demand for Internet access, and draw implications for market definition. We estimate a mixed logit model, in which households choose between different broadband technologies: DSL, cable modem, fibre, WiFi and mobile. We find that a number of household characteristics influence the technology choices, and there is also significant unobserved heterogeneity. Demand for Internet access is highly price sensitive. The price elasticity of demand for DSL is -3.02, which falls in the middle of the range of elasticities for the other technologies. Furthermore, the price elasticity of demand at the level of all fixed broadband technologies $(\mathrm{DSL}+$ cable modem + fibre $+\mathrm{WiFi})$ is equal to -1.98 . For a reasonable range of profit margins, this estimate implies that mobile broadband should be included in the relevant antitrust market of fixed broadband. Our findings have implications for competition policy in Central and Eastern European countries where due to poor copper networks mobile broadband is an important alternative to fixed broadband.
\end{abstract}

Key Words: Broadband, Market Definition, Multinomial Logit, Mixed Logit

JEL Classification: L13, L43, L93

${ }^{*}$ Financial support from Slovak Telekom is gratefully acknowledged. We are also very grateful to Lars-Hendrik Röller, Jakub Kaluzny and Thomas Hildebrand for their comments.

${ }^{\dagger}$ Telecom ParisTech, Department of Economics and Social Sciences, 46 rue Barrault, 75013 Paris, France.

E-mail: lukasz@mushroomski.com

${ }^{\ddagger}$ E.CA Economics, Schlossplatz 1, D-10178 Berlin, Germany. E-mail: nitsche@e-ca.com

$\S$ University of Leuven and CEPR (London), Naamsestraat 69, 3000 Leuven, Belgium. E-mail:

Frank.Verboven@econ.kuleuven.be

『E.CA Economics, Schlossplatz 1, D-10178 Berlin, Germany. E-mail: wiethaus@e-ca.com 


\section{Introduction}

The extent of substitution between fixed-line and mobile telecommunications services has been debated since the early days of mobile telecommunications. This debate bears substantial relevance for market definition and, consequently, for the regulatory and antitrust proceedings. ${ }^{1}$

The historical development of copper based fixed-line infrastructure has differed substantially, in terms of availability and quality, between the Western European (WE) and the post-socialist Central and Eastern European (CEE) countries. In the CEE countries, the telecommunications infrastructure inherited from the socialism era was in a poor condition before the liberalization of the telecommunications markets in the early 2000s, which was the prerequisite for the EU accession). We therefore observe greater shares of households relying on mobile voice services in the CEE countries than in the WE countries. ${ }^{2}$ For the same reason, the development of broadband infrastructure follows a different path. Alternative infrastructures, including mobile broadband access, have a higher share in the CEE countries than in the WE countries, which heavily rely on DSL broadband access.

To date regulators in Europe hesitate to include mobile broadband in relevant broadband antitrust markets (with the notable exception of the Austrian telecommunications regulator RTR), which appears to be driven by a focus the technical and functional differences between fixed and mobile services. ${ }^{3}$ However, given the importance of mobile broadband in the CEE countries we propose a more careful consideration of revealed consumer preferences.

This paper contributes to the discussion on market definition for broadband by providing an econometric analysis of consumer choices of broadband services in Slovakia. We address the question of market definition and substitution between fixed and mobile technologies by estimating price elasticities based on discrete choice models, which take into account the actual choices of consumers. More specifically, we estimate price elasticities based on data from a

\footnotetext{
${ }^{1}$ The first step in merger proceedings and abuse of dominance cases is market definition; that is to identify in a systematic way the competitive constraints that the undertakings face. In many regulatory proceedings the outcome of a market definition may determine whether a firm has significant market power (SMP) in the relevant product market and, hence, whether the National Regulatory Authorities (NRAs) may impose ex ante regulation. In the old telecommunications regulatory framework, a firm was presumed to have an SMP if the share was above $25 \%$ of the relevant product market. In the new regulatory framework, the threshold is more closely aligned with the competition law concept of dominance, i.e., market shares above 40-50\% would lead to a presumption of SMP.

${ }^{2}$ Source: "Special Eurobarometer 362, E-communications Household Survey", 2011.

${ }^{3}$ Mobile and fixed broadband may differ according to the characteristics of mobile and fixed offers (e.g. differences in price, bandwidth, mobility and usage limitations). Some regulators also point to differences in in usage patterns (e.g. some NRAs considered that fixed broadband consumers use the service more intensively and demand higher bandwidth than mobile broadband consumers). Source: "BEREC Report on Impact of Fixed-Mobile Substitution in Market Definition", December 2011
} 
representative survey of 10,000 households conducted by the Gesellschaft fuer Konsumforschung (GfK) in Slovakia (after data cleaning we retain 6,446). Our evidence suggests to extending the market for fixed broadband access towards mobile broadband access. This conclusion may also be relevant for other CEE countries such as Czech Republic and Poland, which feature similar market structures to Slovakia.

Discrete choice models are increasingly used to estimate price elasticities. In the discrete choice set-up, households choose between different broadband technologies, which in our case are: DSL, cable modem, fibre, WiFi and mobile. We estimate a mixed logit model, which controls for observable heterogeneity between households through household characteristics such as household size and income, and in addition allows for unobserved differences through random coefficients. We find that a number of household characteristics influence the technology choices and price sensitivity, and there is also significant unobserved heterogeneity. These findings enable us to account for flexible asymmetric substitution patterns across technologies; that is, cross-price elasticities may differ across different technologies. ${ }^{4}$

Based on the mixed logit model, we find that the demand for Internet access in Slovakia is very price sensitive, with own-price elasticities at the level of individual technologies ranging from -4.94 for $\mathrm{WiFi}$, to -3.06 for cable modem, -3.02 for DSL, -2.75 for fibre and -1.42 for mobile. These elasticities suggest that none of the fixed technologies can be considered as a separate relevant retail market for reasonable margin assumptions. In particular, a 5-10\% DSL price increase would lead to substantial substitution to other technologies, making such a price increase unprofitable.

We then repeat the same exercise for hypothetical price increases for various groups of fixed broadband technologies. The results show that no combination of fixed broadband technologies can be considered to be a relevant retail market. In particular, this is the case if we include all fixed broadband technologies together. We find that the price elasticity of demand for all fixed broadband is equal to -1.98 ; i.e., a price increase in all fixed broadband technologies by $1 \%$ would reduce fixed broadband demand by $1.98 \%$. This elasticity suggests substantial substitution towards mobile broadband and, hence, a relevant antitrust market including mobile broadband,

\footnotetext{
${ }^{4}$ The report by the Body of European Regulators for Electronic Communications (BEREC, 2011) discusses market definition and asymmetric substitution between fixed and mobile telecommunications services mainly due to the mobility feature of the mobile services.
} 
for reasonable margin assumptions. ${ }^{5}$

The elasticities reported above are country-level price elasticities, which measure the effect of a national price increase on total demand (where consumers can only substitute to locally available alternatives). They are most relevant when companies can follow national pricing strategies. We also consider elasticities at the municipality level. These measure the effect of local price increases. In the paper we report the local elasticities for 50 municipalities for which there are sufficient respondents. ${ }^{6}$ For the remaining ones, we provide aggregate statistics. The elasticities at the municipality level confirm the results obtained at the national level. The local elasticities are also high, so that in nearly all municipalities the relevant retail market for DSL includes not only all fixed broadband technologies, but also the mobile technology. The results are robust with respect to various sensitivity tests of the model, which we report in the paper.

The remainder of the article is organized as follows. Section 2 discusses the relevant literature. Section 3 presents the industry background. Section 4 introduces the econometric framework. Section 5 discusses the data used in the estimation. Section 6 presents the estimation results. Finally, Section 7 concludes.

\section{Literature review}

Competition between different technologies for Internet access has increased significantly over the past decade. The degree of subsitutability of different technologies is relevant for antitrust and regulatory cases and has attracted increasing attention. For instance, in 2009, the Austrian telecommunications regulator RTR reviewed and partially deregulated the broadband access market. Based on a market definition for residential consumers that included connections through DSL, mobile broadband and cable modem, RTR concluded that retail broadband access markets were not susceptible to ex-ante regulation. The main reason for this was the growing presence of effective competition due to infrastructure-based competitive pressure exercised by mobile network operators. ${ }^{7}$

\footnotetext{
${ }^{5}$ Substitution in the other direction, from mobile to fixed technologies is lower. Thus, from the perspective of mobile broadband, fixed broadband technologies must not be included in the relevant antitrust market.

${ }^{6}$ There are 79 counties in Slovakia which are divided into 2,930 municipalities. The 50 most populous municipalities represent about $36 \%$ of total population of Slovakia.

${ }^{7}$ Initially, the European Commission raised serious doubts towards this approach by the RTR. After the submission of additional evidence by the RTR, the EC withdrew its serious doubts subject to circumstances
} 
There is a growing body of studies which analyze substitution between different Internet services. Early studies focused on the substitutability of narrowband (dial-up) and broadband access, which was new at that time. For instance, Crandall et al. (2002) use nested logit discrete choice models to analyze demand for Internet access of residential consumers in the US. They find that demand for DSL and cable modem is elastic at -1.18 and -1.22 , respectively, and conclude that DSL and cable modem can be considered to be in the same market of broadband Internet access. In a similar study, Rappoport et al. (2003) use survey data of US households to estimate a nested logit model for choices between dial-up, cable modem and DSL. They find own-price elasticities for cable modem and DSL of -0.587 and -1.462 , respectively. Moreover, dial-up is found not to be a substitute for broadband technologies, while cable modem and DSL are good substitutes for one another. In a study for Portugal, Pereira and Ribeiro (2011) estimate demand elasticities for broadband Internet access using household survey data and a discrete choice model. They find that the demand for DSL and cable modem is very elastic, with elasticities of -2.84 for DSL, -4.86 for cable modem. Demand for broadband access is found to be less sensitive to the price of narrowband access than the demand for narrowband access to the price of broadband access. Ida and Kuroda (2006) estimate a discrete choice model for a survey data in Japan and conclude that the demand for DSL is inelastic at - 0.85 but the demand for cable and fibre Internet access is elastic at -3.15 and -2.50 , respectively. Dutz et al. (2009) estimate a nested logit model using data for 100 Metropolitan Statistical Areas in the U.S. for the years 2005-2008. They find that the price elasticity of DSL decreased from -5.71 in 2005 to -4.04 in 2008 , while broadband elasticity decreased from -1.53 to -0.69 .

In a recent study, Cardona et al. (2009) use household survey data for Austria to estimate discrete choice models for Internet access through DSL, cable and mobile broadband via UMTS. They conclude that the demand for DSL is elastic at -2.55 . Moreover, cable modem and mobile access are found to be close substitutes to DSL and should be included in the relevant antitrust market of DSL. A decline in the elasticity estimates for DSL in areas in which cable modem and mobile broadband are not available is taken as evidence that DSL is significantly constrained closely related to the Austrian market, whilst stressing that fixed and mobile retail broadband services would not normally belong to the same relevant market. The arguments for considering separate fixed and mobile markets are based on technical and functional differences between these technologies rather than on empirical evidence of consumer behavior. See "Case AT/2009/0970: Wholesale broadband access in Austria: Withdrawal of serious doubts and comments pursuant to Article 7(3) of Directive 2002/21/EC" 
by these technologies. Most recently, Srinuan et al. (2012) use a survey data for Sweden to estimate price elasticities of demand for DSL, cable, fiber and mobile Internet. They also find that the demand for DSL is elastic at -2.73 , and the other technologies are close substitutes when they are locally available. ${ }^{8}$

Estimates of price elasticities of demand which stem from discrete choice models are commonly used to draw conclusions on the relevant product market definition based on the SSNIP test and to predict the likely price effects of mergers. For instance, Ivaldi and Lorincz (2011) apply a SSNIP test to the industry of computer servers and find several smaller relevant markets in the low-end segment of servers. Next, they compare results with an alternative methodology, the Full Equilibrium Relevant Market (FERM) test. Nevo (2000) estimates a random coefficients model to study the effects of mergers in the US ready-to-eat cereal industry. Ivaldi and Verboven (2005) analyze the effects of the merger between Volvo and Scania in the EU. Grzybowski and Pereira (2007) estimate unilateral effects of a merger in the mobile telephony in Portugal. Finally, the European Commission uses discrete choice models as evidence for unilateral effects in a merger between producers and sellers of calcium carbonate, Omya and JM Huber (see Durand and Pesaresi (2007)).

\section{Industry background}

\subsection{Broadband technologies}

The deployment of broadband in Slovakia is spread across five different technologies, namely Digital Subscriber Line (DSL), Fixed Wireless Access (or briefly WiFi), cable modem and mobile broadband and fibre (commonly referred to as FTTH). Each of these technologies has achieved a

\footnotetext{
${ }^{8}$ Discrete choice models are also popular for analyzing consumer choices and substitution patterns in fixed-line and mobile telecommunications markets. For instance, Ben-Akiva et al. (1987) use data from US households and a nested logit model to analyze the choices of local telephone tariff plans. They estimate price elasticities of demand for each local service option, number of calls, average duration and revenues with respect to the fixed monthly charges and the usage charges for calling under each option. Lee et al. (2006) use a discrete choice framework and consumer survey data to estimate the effect of number portability on switching costs in the Korean mobile telecommunications industry. Grzybowski and Pereira (2011) estimate price elasticities and switching costs using discrete choice models and consumer survey data for Portugal.
} 
significant coverage. ${ }^{9}$ As of 2009 , the Slovak broadband market was characterized by significant shares of different technologies: DSL (32\%), WiFi (15\%), fibre (16\%), cable modem (8\%) and mobile (29\%). ${ }^{10}$ Compared to other European countries, Slovakia has one of the highest shares of fibre coverage. ${ }^{11}$

A number of historical developments have contributed to a relatively low DSL share and intense infrastructure competition. When Slovak Telekom (ST) entered the broadband sector in 2003 , the penetration of fixed-line telephones accounted for only $24 \%$ of the population. In subsequent years many consumers gave up their fixed-line subscriptions and migrated to mobile telephones. In 2010, fixed-line penetration accounted for $18 \%$ of the population - one of the lowest penetration rates in the EU. ${ }^{12}$ As a result at present, due to network limitations, only $39 \%$ of all households are able to obtain a DSL service (this is referred to as "technical coverage"). Moreover, according to ST about $62 \%$ of Slovak households are covered by ST's DSL network in the sense that they are connected to an active access line which in theory allows for speeds of up to $4 \mathrm{Mbps}$ (this is referred to as "service coverage").

These network limitations and the decline in fixed voice usage due to fixed-to-mobile substitution made the investment in services based on copper infrastructure unattractive for both ST and the other Internet providers. As a result, the development of alternative technologies took off. WiFi and mobile broadband technologies achieved a similar coverage as DSL and the coverage of fibre also increased significantly. Since the end of 2005, the share of DSL in total broadband connections has been declining. Official data from the Slovak Ministry of Transport, Posts and Telecommunications indicates that, in 2010, DSL accounted for approximately $41 \%$ of all fixed Slovak broadband connections. ${ }^{13}$ In March 2011, about $59 \%$ of households declared

\footnotetext{
${ }^{9}$ Penetration of dial-up was historically low in Slovakia compared to the other EU countries because of underdeveloped fixed-line infrastructure.

${ }^{10}$ Source: fixed technologies - Research Institute of Posts and Telecommunications (VUS); mobile broadband - T-mobile, Orange Annual Report 2010

${ }^{11}$ EC DG INFSO - Communications Committee Working Document - Broadband access in the EU: situation at 1 July 2010. Note: EU 27 plus Norway and Iceland.

${ }^{12}$ Ministry of Transport, Posts and Telecommunications, Available at: http://www.telecom.gov.sk/files/statistika_vud/infra_tel.htm

${ }^{13}$ These numbers do not include connections using broadband services over mobile handsets and connections over EDGE / 2.5G networks. If these connections are taken into account, the share of DSL is below 40\%. Source: Ministry of Transport, Communications and Public Works, Number of the Internet subscribers according to technologies - broadband Internet access, available at: http://www.telecom.gov.sk/files/statistika_vud/pristup_tel.htm
} 
to be 'mobile-only' with respect to voice telephony, which is third highest level in the EU after Finland and the Czech Republic. ${ }^{14}$

Mobile broadband is becoming increasingly popular due to expanding coverage and improving technical performance. The connection speed offered by mobile broadband is comparable to the most popular DSL tariffs. There is also an ongoing deployment of a new high-speed mobile data network in HSUPA standard, which is currently supporting data transfer speed rates up to $14.4 \mathrm{Mbps}$ for download and $1.46 \mathrm{Mbps}$ for data upload. ${ }^{15}$ According to the market survey, around $55-60 \%$ of consumers of mobile broadband in Slovakia use it at home. Hence, many households use mobile broadband products as a direct substitute for DSL and other fixed broadband technologies.

\section{Major competitors by technology}

There are significant differences in the number of available technologies in geographic regions, where urban areas offer the largest selection of technologies and suppliers. There is a wide range of DSL products provided by ST (under the T-Com brand) and other providers (SWAN, Slovanet and GTS) offering the same connection speeds at broadly similar prices. The price differentials which can be observed are due to differences in volume allowance (cheaper products tend to have a data limit) and in connection speed.

The main cable TV operator is UPC. It provides broadband access services in all regions in Slovakia. As of the end of June 2011, Internet services from UPC were available to 414,000 households in 22 cities, with a consumer base of about 80,000 households. ${ }^{16}$

The two leading fibre network operators in terms of coverage and consumer base are Slovak Telekom and Orange. In 2011, the fibre network of Orange covered over 300,000 households in 17 cities, i.e., approximately 17\% of all Slovak households, and the number of customers reached $51,000 .{ }^{17}$ In comparison, in 2010, Slovak Telekom's fibre network covered 315,000 households in 19 cities. There is also a number of regional providers which operate fibre networks, including SWAN, Slovanet, Antik, Imafex and Gaya.

There is a wide range of WiFi products offered in Slovakia. About 600 out of over 800

\footnotetext{
${ }^{14}$ Source: "Special Eurobarometer 362, E-communications Household Survey", 2011

${ }^{15}$ Source: Orange Slovensko Annual Report 2010

${ }^{16}$ Source: http://www.telecompaper.com/

${ }^{17}$ Source: http://www.telecompaper.com/
} 
registered local providers of Internet services are local fixed wireless operators. ${ }^{18}$ The products are priced at a comparable level to the other broadband products and offer similar speed of connection. Most WiFi providers are active only locally and many of them started recently to roll out optical fibre networks. As a consequence their consumers are now increasingly migrating from WiFi to fibre.

The leading mobile broadband operator in Slovakia is Orange. ${ }^{19}$ In 2010, the $3 \mathrm{G}$ network of Orange covered more than 3 million consumers in 135 cities and 386 adjacent municipalities. ST's mobile subsidiary T-Mobile Slovakia is ranked second.

\section{Econometric Model}

A discrete choice framework is commonly used to analyze choices of telecommunications services (see Section 2). It is also a natural framework for analyzing consumer decision regarding the mean of Internet access. Each household chooses between a set of discrete alternatives depending on the household characteristics and product attributes. The first step in discrete choice modelling is to define an exhaustive and mutually exclusive choice set and the consumer's decision process, which is commonly represented in the form of a decision tree. Estimates of substitution patterns between alternatives depend on the definition of the choice set and the decision-making process.

In addition to the information on technology which is used by households, the discrete choice methodology requires information on the price of all alternative means of Internet access that were available at the time when each household chose its Internet connection. Provided that price differences significantly impact households' decisions, a matrix of own and cross price elasticities between different means of Internet access can be estimated for each household. Individual price elasticities can then be aggregated for the whole population.

We want to specify a realistic household decision-making process that creates flexible substitution patterns between Internet technologies. The simplest discrete choice model to estimate is the multinomial logit, which generates flexible aggregate substitution patterns when household characteristics are among choice determinants. The model has, however, the property of independence of irrelevant alternatives (IIA), which may result in implausible proportional

\footnotetext{
${ }^{18}$ Source: VUS, http://www.vus.sk

${ }^{19}$ Source: Orange Slovensko Annual Report 2010
} 
substitution patterns across alternatives if there is a lot of unobserved household heterogeneity. Based on these considerations, we first estimate a multinomial logit model with a number of household characteristics to control for observed consumer heterogeneity. We subsequently estimate a mixed logit model, which in addition to household characteristics allows for the unobservable heterogeneity across households. ${ }^{20}$

\subsection{Choice Set}

We first specify each household's set of mutually exclusive and exhaustive choice alternatives. Since our objective is to estimate substitution patterns between different Internet technologies, we specify the choice set as consisting of all technologies available in a given geographic location. We take the following considerations into account.

First, there are significant differences in the availability of technologies in geographic regions. We must therefore allow the choice set to vary geographically, which requires information on the geographic availability of different technologies. Section 5 described how we take the availability of technologies in different geographic locations into consideration.

Second, according to the survey, a significant share of households uses mobile broadband. The survey provides also information on whether mobile broadband is used at home or out of home and whether it is household's main or secondary Internet connection. We consider that a household uses mobile broadband only if it was declared to be used at home and as the main Internet connection.

Our base model specification assumes that the set of choice alternatives consists of no Internet subscription and up to five broadband technologies for Internet access, depending on the geographic availability. The full choice set consists of: (i) DSL; (ii) cable modem; (iii) fibre; (iv) WiFi; (v) mobile; (vi) no Internet.

\subsection{Utility of Internet Access}

We use a standard linear utility specification for households $i=1, \ldots, N$ over the different technologies $j=1, \ldots, J$. Utility depends on technology characteristics and on observable and unob-

\footnotetext{
${ }^{20}$ Mixed logit model allows for rich substitution patterns but it does impose functional form assumptions. This can affect out of sample predictions, for example, when the model is used to predict the effects of mergers. See for example Crooke et al. (1999) and Froeb et al. (2005) for a discussion on the role of functional forms in predicted price effects from mergers.
} 
servable household characteristics. More specifically, let the utility of household $i$ for technology $j$ be given by:

$$
V_{i j}=x_{j}^{\prime} \widetilde{\beta}_{i}-\widetilde{\alpha}_{i} p_{i j}+\epsilon_{i j}
$$

Here, $x_{j}$ is a $J \times 1$ vector of technology dummy variables and $\widetilde{\beta}_{i}$ is a $J \times 1$ vector of coefficients denoting the household-specific valuations for the different technologies (relative to the base no Internet). Furthermore, $p_{i j}$ denotes the price paid by consumer $i$ for technology $j$, and $\widetilde{\alpha}_{i}$ is a random coefficient for the individual-specific valuation of price. Finally, $\epsilon_{i j}$ is a householdspecific valuation for technology $j$, i.e., the "logit error term". It is identically and independently distributed across technologies according to the Type I extreme value distribution.

The vector of coefficients $\widetilde{\beta}_{i}$ and the price coefficient $\widetilde{\alpha}_{i}$ may depend on both observed household characteristics and unobserved heterogeneity. More specifically, we can write:

$$
\left(\begin{array}{c}
\widetilde{\beta}_{i} \\
\widetilde{\alpha}_{i}
\end{array}\right)=\left(\begin{array}{c}
\beta \\
\alpha
\end{array}\right)+\Pi D_{i}+\left(\begin{array}{c}
\sigma_{\beta} \\
\sigma_{\alpha}
\end{array}\right) \nu_{i}, \quad \nu_{i} \sim N(0,1)
$$

where $(\beta, \alpha)$ refers to a $(J+1) \times 1$ vector of mean valuations. $D_{i}$ is a $d \times 1$ vector of observable household characteristics and $\Pi$ a $(J+1) \times d$ matrix of parameters capturing the impact of household characteristics on the valuations for the $J$ technology dummy variables $x_{j}$ and the price variable $p_{j} . \nu_{i}$ is a randomly drawn vector from the standard normal distribution capturing unobserved household heterogeneity regarding price, and $\sigma=\left(\sigma_{\beta}, \sigma_{\alpha}\right)$ refers to a $(J+1) \times 1$ vector of standard deviations around the mean valuations. In our empirical analysis, the vector of observable characteristics $D_{i}$ consists of age, household size, income, a dummy variable for having a fixed line, a dummy variable for the type of housing (apartment versus house), and some other characteristics.

In the special case where $\sigma$ is a vector of zeros, there is no unobserved household heterogeneity and we obtain the conditional logit model as a special case. More generally, we have a mixed or random coefficients logit model, which allows for unobserved in addition to observed heterogeneity between households.

\subsection{Choice Probabilities}

A household $i$ chooses a technology $j$ if this maximizes its utility among all available alternatives, i.e., if $U_{i j}=\max _{k \in C_{i}} U_{i k}$, where $C_{i}$ is household $i$ 's available choice set. Hence, the probability 
that household $i$ with given random coefficients $\widetilde{\beta}_{i}$ and $\widetilde{\alpha}_{i}$ chooses technology $j$ is given by:

$$
\begin{aligned}
l_{i j}\left(\widetilde{\beta}_{i}, \widetilde{\alpha}_{i}\right) & =\operatorname{Pr}\left(U_{i j}=\max _{k \in C_{i}} U_{i k}\right) \\
& =\frac{\exp \left(x_{j}^{\prime} \widetilde{\beta}_{i}-\widetilde{\alpha}_{i} p_{i j}\right)}{\sum_{k \in C_{i}} \exp \left(x_{k}^{\prime} \widetilde{\beta}_{i}-\widetilde{\alpha}_{i} p_{i k}\right)}
\end{aligned}
$$

where the second line follows from the distributional assumptions of the logit error term $\epsilon_{i j t}$. If there is no unobserved household heterogeneity $(\sigma=0)$, this is the standard multinomial logit choice probability that enters the likelihood function. With unobserved heterogeneity, it is necessary to integrate the conditional choice probability $l_{i j}\left(\widetilde{\beta}_{i}, \widetilde{\alpha}_{i}\right)$ over the distribution of $\widetilde{\alpha}_{i}$ and $\widetilde{\beta}_{i}$ :

$$
s_{i j}=\int_{\widetilde{\alpha}} \int_{\widetilde{\beta}} l_{i j}(\widetilde{\beta}, \widetilde{\alpha}) f(\widetilde{\alpha}) f(\widetilde{\beta}) d \widetilde{\alpha} d \widetilde{\beta}
$$

where we specified the distribution of $\widetilde{\alpha}_{i}$ and $\widetilde{\beta}_{i}$ earlier in (2) to consist of an observable part and an unobservable part that is normally distributed, $\nu_{i} \sim N(0,1)$. This is the mixed logit or random coefficients logit choice probability.

\subsection{Estimation Strategy}

We can express household $i$ 's probability of choosing the alternative that it actually made as $\prod_{j} s_{i j}^{y_{i j}}$, where $y_{i j}=1$ if household $i$ chose alternative $j$ and $y_{i j}=0$ otherwise. Assuming that each household's choice is independent of choices of other households, the probability that each household in the sample chooses the alternative which it was observed to choose can be written as the log-likelihood function:

$$
\mathcal{L}(\theta)=y_{i j} \sum_{i}^{N} \sum_{j} \log \left(s_{i j}\right) .
$$

where $\theta$ is the vector of all parameters to be estimated. To approximate the integral entering the choice probabilities $s_{i j}$ given by equation (3), we use simulation method. Following Train (2003), we take $R$ Halton draws for the vector $\nu_{i}$ from the standard normal distribution to obtain the average choice probability per household:

$$
\widehat{s}_{i j}=\frac{1}{R} \sum_{r=1}^{R} \frac{\exp \left(x_{j}^{\prime}\left(\beta+\sigma_{\beta} \nu_{i}^{r}\right)-\left(\alpha+\sigma_{\alpha} \nu_{i}^{r}\right) p_{i j}+\left(x_{j}^{\prime}, p_{i j}\right) \Pi D_{i}\right)}{\sum_{k \in C_{i}} \exp \left(x_{k}^{\prime}\left(\beta+\sigma_{\beta} \nu_{i}^{r}\right)-\left(\alpha+\sigma_{\alpha} \nu_{i}^{r}\right) p_{i k}+\left(x_{k}^{\prime}, p_{i k}\right) \Pi D_{i}\right)} .
$$


In the special case of no unobserved household heterogeneity $(\sigma=0)$, this reduces to the multinomial choice probability:

$$
\widehat{s}_{i j}=\frac{\exp \left(x_{j}^{\prime} \beta-\alpha p_{i j}+\left(x_{j}^{\prime}, p_{i j}\right) \Pi D_{i}\right)}{\sum_{k \in C_{i}} \exp \left(x_{k}^{\prime} \beta-\alpha p_{i k}+\left(x_{k}^{\prime}, p_{i k}\right) \Pi D_{i}\right)} .
$$

The maximum simulated likelihood estimator is the value of the parameter vector $\theta$ that maximizes the likelihood function $\mathcal{L}$ given by equation (4), after substituting formula (5) into $s_{i j}$. 21

\subsection{Price Elasticities of Demand}

The multinomial and mixed logit models can be used to calculate the price elasticities of demand. We are interested in:

- the own-price and cross-price elasticities of demand at the level of the individual technologies;

- the own-price elasticity of total fixed broadband demand, i.e., at the level all fixed technologies, DSL, cable modem, fibre and WiFi; and

- the price elasticity at the level of total broadband demand (fixed+mobile), i.e., DSL, cable modem, fibre, WiFi and mobile.

We calculate these elasticities at two levels of geographic aggregation: the municipality and the country.

Technology-level elasticities Technology-level elasticity is a percentage change in demand for a technology in response to a $1 \%$ change in the price of this technology (own-price elasticity) or $1 \%$ change in the price of another technology (cross-price elasticity). To calculate the ownand cross-price elasticities at the level of the individual technologies we proceed as follows. Let the aggregate market share for technology $j$ be given by $s_{j} \equiv \sum_{i} s_{i j} / N$, where $N$ is the number of households in the considered geographic region which can be municipality or the whole country and $s_{i j}$ is a probability that household i chooses technology $\mathrm{j}$. The effect of a

\footnotetext{
${ }^{21}$ The algorithm for estimating a mixed logit model is explained in detail in Train (2003).
} 
percentage price increase of technology $k$ on the level of individual household $i$ 's probability of choosing technology $j$ is:

$$
\frac{\partial s_{i j}}{\partial p_{i k}} p_{i k}=\left\{\begin{array}{ll}
-\widetilde{\alpha}_{i} s_{i j}\left(1-s_{i j}\right) p_{i j} & \text { if } \mathrm{k}=\mathrm{j} \\
\widetilde{\alpha}_{i} s_{i j} s_{i k} p_{i k} & \text { otherwise }
\end{array} .\right.
$$

This could also be called individual household $i$ 's semi-elasticity of demand for $j$ with respect to the price of $k$. Summing over all households in the region $s_{j} \equiv \sum_{i} s_{i j} / N$, the aggregate technology-level semi-elasticity may simply be defined as the sum:

$$
\frac{1}{N} \sum_{i} \frac{\partial s_{i j}}{\partial p_{i k}} p_{i k}=\left\{\begin{array}{ll}
\frac{1}{N} \sum_{i}\left(-\widetilde{\alpha}_{i}\right) s_{i j}\left(1-s_{i j}\right) p_{i j} & \text { if } \mathrm{k}=\mathrm{j} \\
\frac{1}{N} \sum_{i} \widetilde{\alpha}_{i} s_{i j} s_{i k} p_{i k} & \text { otherwise }
\end{array} .\right.
$$

This is the effect of a percentage price increase on the level of aggregate demand for technology $j$. The aggregate technology-level elasticity of demand for technology $j$ with respect to the price of $k$ may be defined as:

$$
\varepsilon_{j k}=\frac{1}{N}\left(\sum_{i} \frac{\partial s_{i j}}{\partial p_{i k}} p_{i k}\right) \frac{1}{s_{j}}=\left\{\begin{array}{ll}
\sum_{i}\left(-\widetilde{\alpha}_{i}\right) s_{i j}\left(1-s_{i j}\right) p_{i j} / \sum_{i} s_{i j} & \text { if } \mathrm{k}=\mathrm{j} \\
\sum_{i} \widetilde{\alpha}_{i} s_{i j} s_{i k} p_{i k} / \sum_{i} s_{i j} & \text { otherwise }
\end{array} .\right.
$$

Group-level elasticities Group-level elasticity is a percentage change in demand for a group of technologies in response to a $1 \%$ change in the price of all technologies in this group. To calculate the price elasticity at the level of a group of technologies $j \in \delta$ (e.g. DSL, cable modem, fibre and $\mathrm{WiFi}$ ) we proceed as follows. Let the aggregate market share for technologies $j \in \delta$ be given by $s_{\delta} \equiv \sum_{i} \sum_{j \in \delta} s_{i j} / N$, where $N$ is the number of households in the considered geographic region. The effect of a percentage price increase of technologies belonging to $\delta$ on the level of the individual probability of choosing from the group $\delta$ is:

$$
\sum_{j \in \delta} \sum_{k \in \delta} \frac{\partial s_{i j}}{\partial p_{i k}} p_{i k}=-\widetilde{\alpha}_{i} \sum_{k \in \delta} s_{i k} p_{i k}\left(1-\sum_{j \in \delta} s_{i j}\right)
$$

Summing over all households in the region $s_{\delta} \equiv \sum_{i} \sum_{j \in \delta} s_{i j} / N$, the aggregate group-level semi-elasticity may simply be defined as the sum:

$$
\frac{1}{N} \sum_{i}\left[\sum_{j \in \delta} \sum_{k \in \delta} \frac{\partial s_{i j}}{\partial p_{i k}} p_{i k}\right]=\frac{1}{N} \sum_{i}\left(-\widetilde{\alpha}_{i}\right)\left[\sum_{j \in \delta} s_{i k} p_{i k}\left(1-\sum_{j \in \delta} s_{i j}\right)\right] .
$$

This is the effect of a joint percentage price increase of all technologies in group $\delta$ on the level of aggregate demand for technologies in group $\delta$. The aggregate group-level elasticity of demand 
for the group of technologies $\delta$ with respect to a joint percentage price increase may then be defined as:

$$
\varepsilon_{\delta}=\frac{1}{N} \sum_{i}\left[\sum_{j \in \delta} \sum_{k \in \delta} \frac{\partial s_{i j}}{\partial p_{i k}} p_{i k}\right] \frac{1}{s_{\delta}}=\sum_{i}\left(-\widetilde{\alpha}_{i}\right)\left[\sum_{k \in \delta} s_{i k} p_{i k}\left(1-\sum_{j \in \delta} s_{i j}\right)\right] / \sum_{i} \sum_{j \in \delta} s_{i j} .
$$

We calculate the group-level elasticity implied by the estimates for the group consisting of all fixed broadband technologies, i.e., DSL, cable modem, fibre and WiFi. The same formula can also be used for other groups. In particular, we calculate the elasticity at the level of the entire market, i.e., all broadband technologies including mobile.

Municipality-level versus country-level elasticities We calculate the elasticities at two levels of geographic aggregation. Municipality-level elasticities refer to the effect of a percentage price increase on total demand within a given municipality. Country-level elasticities refer to the effect of a percentage price increase on total demand in the entire country. We can thus distinguish between the effects of uniform percentage price increases at the municipal and national levels. As such, we can consider whether the results are robust when companies can follow only national or local pricing policies. In Section 6 we present municipal-level elasticities for the 50 largest municipalities in terms of the number of respondents out of 2,930, and take an average for the remaining ones with a smaller number of respondents.

Our approach thus considers the effect of a percentage price increase on aggregate demand of all households within a region (municipality or country). This approach to the calculation of price elasticities is in the spirit of competition policy. Our approach differs from some other studies. For instance, Pereira and Ribeiro (2011) calculate average household-level elasticities instead of aggregate elasticities. ${ }^{22}$

\footnotetext{
${ }^{22}$ More specifically, they first compute individual household elasticities

$$
\varepsilon_{i j k}=\frac{\partial s_{i j}}{\partial p_{i k}} \frac{p_{i k}}{s_{i j}}=\left\{\begin{array}{ll}
-\alpha\left(1-s_{i j}\right) p_{i j} & \text { if } \mathrm{k}=\mathrm{j} \\
\alpha s_{i k} p_{i k} & \text { otherwise }
\end{array},\right.
$$

and then simply average this over all households to obtain $\bar{\varepsilon}_{j k}=\sum_{i} \varepsilon_{i j k} / N$. These average elasticities are not equivalent to our country-level aggregate elasticities. In practice, they turn out to be much larger. The average household-level elasticities in Pereiro and Ribeiro (2011) are also not equivalent to our municipality-level elasticities. But they are closely related because we present the average municipality-level elasticities for the smaller ones. If there was only one household per municipality, both approaches would be equivalent.
} 


\section{Data}

\section{$5.1 \quad$ Data sources}

To estimate the choice models we combine three data bases which are discussed below in detail:

- Database of a GfK telephone survey conducted on 10,000 households in Slovakia.

- VUS database providing information on the availability of different Internet technologies at the municipality level in Slovakia in the first quarter of 2010.

- Database of broadband Internet tariffs in Slovakia collected from online sources in the second quarter of 2011 for 47 main Internet providers in Slovakia according to GfK survey statistics (252 tariffs).

GfK survey data The GfK telephone survey was conducted in Slovakia in two waves in April 2011 (a pre-sample of 1,000 households) and in July 2011 (main sample of 9,000 households). ${ }^{23}$ The sample size is much larger than commonly used in empirical studies for market definition, especially taking into account the fact that the population of Slovakia is relatively small (about 5.4 million).

For each household, the survey contains detailed information on the Internet connection. For the purpose of our study, the following information is of particular importance: identity of the main Internet provider; technology of the main Internet connection; average monthly payment for the main connection; municipality of residence; year in which use of current main connection started.

The survey includes also a number of household characteristics, which are used as explanatory variables in the model: size of the household (continuous variable truncated by 5 ); housing type, i.e., apartment versus house (dummy variable equal to 1 if apartment and 0 if house); net monthly income (continuous variable); age of the respondent (continuous variable); gender of

\footnotetext{
${ }^{23}$ The GfK survey was conducted through phone calls to mobile numbers because calls to fixed networks were likely to produce a bias: the share of Slovak households with a fixed telephone line is low and therefore households with fixed-line connection are not representative of the whole population. In contrast, mobile phone penetration in Slovakia is well above $100 \%$ of population. According to Eurobarometer, in 2010, only about $8 \%$ of households in Slovakia had fixed-line access but no mobile access and additional $6 \%$ did not use telecommunications services at all. (Source: "Special Eurobarometer 362, E-communications Household Survey", 2011.)
} 
the respondent (dummy variable equal to 1 if the respondent is male); use of another Internet connection before the current one (dummy variable equal to 1 if the household reports to have had another Internet connection before the current one); having fixed-line connection (dummy variable equal to 1 if the household has a fixed-line connection); having Internet bundled with TV (dummy variable equal to 1 if the household has TV channels bundled with Internet); having a secondary Internet connection (dummy variable equal to 1 if the household has a second Internet connection). The household characteristics are interacted with the price variable and five different technology dummies, using the sixth option 'no Internet' as the base, with respect to which we interpret all technology parameters.

The survey includes 8,000 Internet and 2,000 non-Internet households. This implies an under-sampling of non-Internet households because according to official statistics, the percentage of Internet households in Slovakia by the end of 2010 was about $50 \%{ }^{24}$ To correct for the under-sampling of households without Internet, for each non-Internet household we generate 3 additional observations with the same characteristics, which is a common statistical approach. ${ }^{25}$

VUS database The VUS database contains information on the availability of different Internet technologies at the municipality level in Slovakia in the first quarter of 2010. For each of the 2,930 municipalities in Slovakia and 7 broadband technologies (DSL, CATV, FTTx, WiMax, WiFi, FLASH-OFDM ${ }^{26}$ and G3) there is a binary indicator showing whether a particular technology is available in a given municipality. We denote technologies WiMax and WiFi as WiFi, and Flash and G3 as mobile broadband. The database then contains information on the availability of five technologies: DSL, cable modem, fibre, WiFi and mobile broadband.

Tariffs database A database of broadband Internet tariffs was assembled in the second quarter of 2011 from the Internet websites of the main Internet providers in Slovakia. Among the information collected were: (i) identity of the provider, (ii) name of the tariff, (iii) maximum

\footnotetext{
${ }^{24}$ Source: "Special Eurobarometer 335, E-communications Household Survey", 2010.

${ }^{25}$ The non-Internet households were undersampled by purpose because there was a primarily interest in households with different Internet connections and the survey was costly.

${ }^{26}$ FLASH denotes Fast Low Latency Access with Seamless Handoff and OFDM denotes Orthogonal Frequency Division Multiplex. In Slovakia, FLASH-OFDM technology is used by T-mobile for providing mobile broadband using $450 \mathrm{MHz}$ spectrum. It provides connections with a maximum effective download speed of $5.3 \mathrm{Mbit} / \mathrm{s}$, and a maximum upload speed of $1.8 \mathrm{Mbit} / \mathrm{s}$.
} 
download speed, (iv) data download limit, (v) installation charge, (vi) payment for equipment, (vii) commitment period, (viii) whether the tariff was part of a bundle with fixed-line or TV, and (ix) monthly list price and promotional discounts.

This database contains 1,015 different tariffs for 47 Internet providers with the greatest number of subscribers according to GfK survey data. The data was processed and narrowed down to 252 tariffs for 45 providers based on a specified tariff selection algorithm and our best judgement. The reason for limiting the number of tariffs was to use pricing information which is comparable across providers and can thus be applied in the econometric analysis. ${ }^{27}$

We compute the average monthly price of using Internet services for the 24-month commitment period, to which we refer as price. We define this average monthly price as: [(monthly list price $) \times(24-\mathrm{X})+($ promotional price $) \times \mathrm{X}+($ installation price $)-($ Internet discount $)] / 24$, where: (i) the monthly list price is the advertised monthly price, (ii) the promotional price is the discounted price charged for the initial X months of the contract, (iii) the installation price is the one-off cost of starting the Internet connection, (iv) Internet discount is the one-off discount offered to clients who subscribe online.

\subsection{Data handling}

We use these data bases to determine the choice sets of broadband technologies which are available to each individual household. For each choice alternative we also need to determine

\footnotetext{
${ }^{27}$ There are many similar tariffs which differ in price because of differences in the length of commitment period and in the price of installation. Usually, the longer is the commitment period or the higher is the price of installation the lower is the monthly price. We focused on tariffs with a 24-month commitment period (or closest to a 24-month commitment period), which according to industry experts are most commonly chosen by consumers. By choosing tariffs with the same commitment period, we ensure comparability of prices across providers and technologies. Moreover, according to industry experts, providers typically tend to offer tariffs which are targeted at three different groups of consumers with respect to usage intensity: low, medium and high usage profiles. We tried to assign each tariff in the database to one of these profiles. We neglected tariffs which appear to be variations of other base tariffs. We also neglected tariffs with high installation fees, unless these were the only tariffs offered. Furthermore, we focused on tariffs without additional terms and conditions such as loyalty schemes, etc., unless these were the only tariffs offered. For each provider we picked tariffs in a broad price range to have a closer match between tariffs and respondents' declared fees. At the end, we selected 313 tariffs using these criteria. In the process of matching tariffs with survey database we lose some of them because there are provider/technology pairs which appear not to be selected by any of the survey respondents. The final number of tariffs used in the estimation is 252 .
} 
price.

Determining the choice sets of individual households Since the main purpose of the model is to determine substitution patterns between different technologies, we model the choice set of a given household as the set of available technology/price pairs at the location of the household. The set of technologies available to each household is determined by merging the survey data with the VUS database on the availability of different Internet technologies at the municipality level. In this way, for each household in the survey we obtain information on the availability of five different technologies in the municipality where the household is residing. In addition, households can always decide not to have Internet access at all.

Determining the prices of different choices Each of the technologies available to households residing in a particular municipality must be assigned a unique price, which involves the steps described below. However, since in Slovakia there are 79 counties divided into 2,930 municipalities, we have only few respondents for less populous municipalities. We therefore first determine prices on a county level and then use them for choice sets determined on the municipality level.

- In the survey, households provide information on the municipality of their residence, and on the chosen provider and technology. This information can be used to create a list of all provider/technology pairs by municipality, whenever at least one household from this municipality declared using a given provider/technology pair. ${ }^{28}$ This list is then aggregated to a county level including all provider/technology pairs that are available in at least one municipality in the county. ${ }^{29}$

- Next, this information on provider/technology pairs is matched with the tariffs database to create a list of all tariffs available for a given technology in a given county. Thus, for each household which resides in a given county there is a range of available providers,

\footnotetext{
${ }^{28} \mathrm{GfK}$ conducted a similar survey to the one used in this analysis in July-September 2010. To increase the number of observations in our final sample we compile information on availability of provider/technology from both the 2011 and the 2010 surveys, which together before data cleaning include 16,000 observations on provider/technology pairs chosen by households.

${ }^{29}$ There may be instances, in which we assume that a certain provider/technology pair is available in the whole county, while in reality it is only available in a single municipality in this county.
} 
technologies and tariffs. In some cases, a survey respondent reported use of technology that was marked as unavailable in a given municipality according to the VUS data. We expanded the choice set in such cases, assuming that the reported technology was indeed available to all households residing in this municipality, if at least two households reported using it. The VUS data is from the second quarter of 2010 and some technologies could have become available within the last year.

- We determine the price of the selected and non-selected alternatives as follows:

- We assume that the price of selected alternative is given by the price of tariff offered by the selected provider for the selected technology, which is the closest to what the household declared as the average monthly price paid. In the matching process we also take additional criteria into account, such as whether the tariff used has limited download volume or is part of a bundle with a fixed-line or TV. ${ }^{30}$

- We assume that the price of non-selected alternatives is represented by the average value of all tariffs available for a given technology in the county where the household is residing, weighted by the providers' local market shares. The underlying assumption is that households have limited information about prices of available alternative technologies and form expectations about monthly prices which can be represented by the weighted average values of all available tariffs for a given technology. The weights are calculated from the survey data by taking the number of households using a given provider and technology in a county and dividing it by the total number of households using the respective technology in this county. ${ }^{31}$

Further assumptions We were only able to collect tariff information for the second quarter of 2011, while many households decided about broadband access before this date and may be

\footnotetext{
${ }^{30}$ The majority of households (about 95\%) provided information on the average monthly price for using the Internet. For households for which this information is missing, out-of-sample predictions were made based on a regression analysis conducted for the first group, in which the average monthly price was regressed on individual characteristics and information on usage intensity.

${ }^{31} \mathrm{An}$ alternative approach is to incorporate the information on whether a household uses a bundled tariff. For households which declared using a non-bundled tariff, the price of non-selected alternatives can be approximated by an average of all non-bundled tariffs for the technology in the county where it is located. We have also estimated the model presented in this paper under this assumption, which gave broadly similar results.
} 
locked-in by contracts. We need to assume that these prices are valid for decisions on the technology choice of all households without regard for the time of subscription. This is also a common assumption in the relevant literature, including Cordona et al. (2009) and Pereira and Ribeiro (2011).

We do not model choices of dial-up technology. Due to the historical underdevelopment of fixed-line telephony in Slovakia, there was a relatively small number of dial-up users. The majority of households which reported using dial-up are clients of ST and according to ST the majority of these households can be in fact considered as DSL users. Hence, we assume that all of ST's dial-up households are DSL users and we dropped from the sample households which declared using dial-up from other providers. ${ }^{32}$ We justify this assumption on the basis of a small market share of dial-up relative to other technologies. ${ }^{33}$

\subsection{Final sample statistics}

The initial number of 8,000 Internet households in the survey is reduced to 6,446 due to several data limitations. We lose the following number of households: (i) 435 due to missing information on the technology used; (ii) 354 households declared the use of other fixed cable connection to access the Internet and are dropped; ${ }^{34}$ (iii) 57 households declared using mobile phones to access the Internet and are dropped; ${ }^{35}$ (iv) 391 households declared using dial-up from another provider

\footnotetext{
${ }^{32}$ Alternatively, we could drop all households which declared using dial-up including ST consumers. This slightly changes the market shares of the technologies and increases the share of outside option, which in turn slightly increases the price elasticities, and therefore has no impact on our conclusions regarding market definition. In particular, for the mixed logit model the price elasticity for fixed broadband technologies increases from -1.98 to -2.04 and the elasticity for all broadband technologies increases from -1.51 to -1.56 .

${ }^{33}$ In the previous antitrust cases narrowband and broadband were considered to be in separate markets. In the Commission vs Wanadoo Interactive case in France in 2003, the Commission found that the retail prices charged by Wanadoo for Internet access through DSL were below cost for a period of time, which restricted market entry and the development potential of competitors. The Commission stated that the relevant market in this case was high-speed Internet access (up to $512 \mathrm{kbit} / \mathrm{s}$ ) for residential consumers because subscribers to low-speed and high-speed had distinct profiles and high-speed Internet access modems could not be used for low-speed access and vice versa. Also, migration from low-speed to high speed was much more prevalent than in the opposite direction. See also Hausman et al. (2001) for an econometric study for broadband access in the US.

${ }^{34}$ We exclude households which access the Internet by using fixed non-fibre cable connection from the analysis because there is no pricing information.

${ }^{35}$ Since Internet use via mobile phones may be a close substitute to mobile broadband, by dropping these households we reduce the share of mobile Internet users, which is conservative with regard to the market definition.
} 
than ST and are dropped; (v) 1,121 are lost during the tariff matching process; (vi) 16 households are dropped because their provider was taken over according to industry experts; (vii) 76 are lost due to missing data on the type of dwelling; (viii) 63 are lost because they have only one broadband technology choice available according to VUS technology availability data. Hence, the data loss is mainly due to a lack of information on the usage of broadband technologies or lack of tariff data in the case of households who declared using small providers. In total, due to different reasons we lose 2,513 households, which leaves us with 5,580 Internet households and 1,907 non-Internet households.

We further restrict attention to a sub-sample of households who started their current Internet connection after 2006, which reduces the number of Internet households to 4,126. The motivation for this restriction is that the availability of alternative technologies was limited before 2007 and many households did not have the same choice of technologies which they have now. ${ }^{36}$ Moreover, most of the growth of the broadband market in Slovakia took place after 2006. ${ }^{37}$ About $74 \%$ of Internet households in our sample began using broadband after this date. Hence, entrants focused on acquisition of new clients rather than on competition for those who already were broadband users.

Among non-Internet households there may be some which are not interested in using the Internet at all. These households should not be considered as part of the potential market. The number of households who are not interested in having Internet connection at all is determined on the basis of a survey question, in which households were asked about plans to set up an Internet connection in the next 12 months. Households which answered 'definitely yes' or 'rather yes' were considered to be 'no Internet' households in the base-model specification. Households which answered 'rather not' or 'definitely not' were not considered to be part of the market and were consequently excluded from the sample. ${ }^{38}$ This step limits the number of non-Internet households from 1,907 to 580 .

Next, we correct for the under-sampling of non-Internet households which gives $580 \times 4=$

The share of households using mobile phones to access Internet is nevertheless below $1 \%$.

${ }^{36}$ The fact that the availability of alternative technologies has increased over time is visible in the VUS data.

${ }^{37}$ Source: Eurostat.

${ }^{38} \mathrm{An}$ alternative assumption is that the latter households may still be interested in having an Internet connection at lower prices. With regard to the market definition, our assumption to exclude these households is conservative because it tends to yield lower elasticities. Intuitively, all else being equal, if there are fewer households who decide not to use broadband this means that the price elasticity of demand is lower. 
Table 1: Sample

\begin{tabular}{|l||c|c||c|c|}
\hline \hline & weighted & $\%$ & non-weighted & $\%$ \\
\hline cable modem & 346 & $5 \%$ & 346 & $7 \%$ \\
\hline DSL & 1,600 & $25 \%$ & 1,600 & $34 \%$ \\
\hline fibre & 1,092 & $17 \%$ & 1,092 & $23 \%$ \\
\hline WiFi & 165 & $3 \%$ & 165 & $4 \%$ \\
\hline mobile & 923 & $14 \%$ & 923 & $20 \%$ \\
\hline No Internet & 2,320 & $36 \%$ & 580 & $12 \%$ \\
\hline Total & 6,446 & $100 \%$ & 4,706 & $100 \%$ \\
\hline \hline
\end{tabular}

The under-sampling of Internet households is corrected by generating for each non-Internet household 3 cloned observations with the same characteristics. After correction the share of non-Internet households in the sample is $50 \%$, which is equivalent to the share of non-Internet households in the whole population in 2011. But some of the non-Internet households declared no interest in having Internet and they are not considered to be decision makers at all, which reduces the share of non-Internet households in the estimation sample to $36 \%$.

2,320 non-Internet households. ${ }^{39}$ After this step, the final sample size used in the estimation is $6,446(2,320+4,126)$, as shown in Table 1 , broken down by technology.

Table 2 shows the distribution of households in the sample used in the estimation by the year in which they started using their current Internet connection.

Table 3 shows the frequency of households having a certain number of technology choices according to VUS data.

\section{Empirical results}

\subsection{Overview}

We first estimate a simple multinomial logit model, which only allows for observed household heterogeneity. We then extend the analysis to a mixed logit model, which allows for both observed

\footnotetext{
${ }^{39}$ In February 2011, about $50 \%$ of households in Slovakia reported having Internet access. In the survey we have 2,000 randomly selected non-Internet and 8,000 randomly selected Internet households. After cloning each of the non-Internet households three times, we end up with 8,000 non-Internet households, which represent $50 \%$ in our initial sample, as can be observed in the general population.
} 
Table 2: Households by Internet starting date

\begin{tabular}{|l||c|c|c|c|c|c|}
\hline \hline & 2007 & 2008 & 2009 & 2010 & 2011 & Total \\
\hline \hline cable modem & 46 & 55 & 92 & 96 & 57 & 346 \\
\hline DSL & 329 & 376 & 461 & 299 & 135 & 1,600 \\
\hline fibre & 124 & 217 & 327 & 306 & 118 & 1,092 \\
\hline mobile & 110 & 186 & 303 & 225 & 99 & 923 \\
\hline No Internet & 0 & 0 & 0 & 0 & 2,320 & 2,320 \\
\hline WiFi & 27 & 45 & 56 & 25 & 12 & 165 \\
\hline Total & 636 & 879 & 1,239 & 951 & 2,741 & 6,446 \\
\hline \hline
\end{tabular}

The sample of 6,446 households used in the estimation consists of households which started using current Internet connection from 2007 onwards.

Table 3: Available technologies

\begin{tabular}{|l||c|c|}
\hline \hline Available technologies & Households & $\%$ \\
\hline 1 & 370 & $6 \%$ \\
\hline 2 & 1,002 & $15 \%$ \\
\hline 3 & 1,663 & $26 \%$ \\
\hline 4 & 1,269 & $20 \%$ \\
\hline 5 & 2,142 & $33 \%$ \\
\hline Total & 6,446 & $100 \%$ \\
\hline
\end{tabular}

The frequency of households having a certain number of technology choices according to VUS data. 
and unobserved heterogeneity with respect to technology valuations. A likelihood-ratio test indicates that the mixed logit is preferred over the multinomial logit model: the test statistic is equal to $\chi^{2}=-2 \ln \left(L_{0} / L_{1}\right)=394$, while the critical value at $1 \%$ confidence level for three degree of freedom (three additional random coefficients) is equal to $\chi^{2}(0.01,1)=11.34$. Therefore, we focus our discussion on more general mixed logit model, and for completeness report the estimates of the multinomial logit model in the appendix in Table 8.

We begin by presenting the parameter estimates in subsection 6.2 . We then discuss how these parameters translate into own- and cross-price elasticities of demand. Subsection 6.3 considers the price elasticities at the country-level, which correspond to a hypothetical percentage price increase applicable throughout the entire country. Subsection 6.4 considers price elasticities at the level of the municipality, which correspond to a hypothetical price increases applicable only in a given municipality. The country-level elasticities are relevant to perform market definition if firms are constrained to a national pricing policy. The municipality-level elasticities are relevant to perform market definition if firms can follow local pricing policies. Subsection 6.5 discusses the findings of an extensive sensitivity analysis. Finally, subsection 6.6 discusses the implications for market definition.

\subsection{Parameter estimates}

The mixed logit model is a generalization of the multinomial logit, allowing for both observed and unobserved heterogeneity with respect to technology valuations. The included observed household characteristics that may affect the choice of broadband technology are: age, sex, household size, income, living in an apartment, fixed-line subscription, and previous Internet connection. All these household characteristics are interacted with technology dummies and with the price variable.

Unobserved household heterogeneity is accounted for in two ways. First, we include a random coefficient for price, thus allowing for unobserved heterogeneity in price sensitivity, which is common in the random coefficients logit literature, e.g., Nevo (2000). Second, we include random coefficients for two dummy variables: one for mobile broadband and another one for all fixed broadband technologies. Such specification considers that consumers have correlated tastes for the fixed versus mobile technologies, relative to the base (no broadband). Note that the random coefficients on these two dummy variables capture similar effects to the nesting parameters in a 
nested logit model with one nest for the mobile technology, one nest for the fixed technologies, and a nest for the outside option (no broadband). Yet our approach is more general than nested logit because it also includes a random coefficient on the continuous price variable. ${ }^{40}$

The estimation results are presented in Table 8 in the appendix. Although our main interest is in the price coefficient, we first discuss the effect of observed household characteristics on the technology valuations (relative to the base "no Internet"). Age has a significant negative impact on the adoption of all broadband technologies, relative to the base category of no Internet adoption. Hence, households with older survey respondents are less likely to adopt broadband. Households for which the respondent was male tend to be more likely to adopt a broadband technology than female respondents, though for mobile broadband the gender difference is insignificant. Household size does not significantly affect the choice of internet technology. Households living in an apartment are typically less likely to adopt broadband than households living in a house, with the exception is broadband access via cable modem, which may be due to the fact that it is easier to deploy cable network in apartment blocks, especially in new apartments. Households with a fixed-line connection appear less likely to have broadband, especially fibre and cable modem. This may be due to bundling of copper fixed-line connection with DSL, which reduces incentives to adopt alternative broadband technologies. Finally, households who already had another Internet connection previously are also less likely to adopt fixed broadband, especially DSL and fibre. There are therefore relatively more households adopting mobile broadband and WiFi over time, which can be attributed to increasing quality and availability of these technologies.

The price coefficient is most interesting for us because our objective is to estimate price elasticities and to define the relevant market. The price coefficient is negative and highly significant, which indicates that households are price sensitive. The interactions with household characteristics indicate the following. Consistent with other demand studies, the price sensitivity tends to be lower for high income households. Furthermore, households with a male respondent are more price sensitive than households with a female respondent. This may be because men are usually

\footnotetext{
${ }^{40}$ We also estimate a number of alternative specifications for the mixed logit model. In particular, we allow for random coefficients on technology dummies and price in models with and without price interactions. We assess how excluding some of the explanatory variables influences the estimated random coefficients. In general, we find that the random coefficients on the technology dummies, except mobile broadband, tend to be insignificant in models with price interactions. The random coefficient on price is always highly significant.
} 
more technology interested and may be therefore better informed. Also, households with older survey respondents have lower price elasticity, which may be because they are less informed. The price sensitivity is also lower for larger households, which may be because the cost is shared among more users. The price sensitivity is also lower for households living in an apartment, with a fixed-line connection, and who had another Internet connection before. ${ }^{41}$

The random coefficient for the price variable shows that there is significant unobserved heterogeneity in the price sensitivity: the mean valuation of -0.688 and the standard deviation of 0.031 are both highly significant. At the same time, the standard deviation is sufficiently small, so that individual price coefficient is negative for all households.

Finally, the random coefficient for the mobile dummy is significant but the one for the fixed dummy is not. This means that there is significant unobserved heterogeneity for the valuation of mobile broadband, relative to the valuation for fixed and 'no broadband'.

\subsection{Price elasticities at the country level}

What do these parameter estimates imply for the price elasticities? In this subsection we comment on country-level elasticities, and discuss municipality-level elasticities in the next subsection.

The country-level elasticities measure the effects of country-level price increase on total demand of all households in Slovakia. We begin with the own- and cross-price elasticities of the five individual technologies (cable, DSL, fibre, WiFi and mobile), as shown in the top matrix of Table 4. The elasticities are computed using formula (6) but accounting for the random coefficients. For each household we draw 200 random numbers from the normal distributions implied by the estimates of the random coefficients.

For all technologies, households are highly price sensitive. The price elasticity for DSL is -3.02 , meaning that a $1 \%$ price increase for DSL reduces DSL demand by $-3.02 \%$. The other

\footnotetext{
${ }^{41}$ There are some differences in non-price characteristics between technologies. In particular, speed and quality of connection differ between technologies and geographic regions. The technology dummies which we use in the estimation may pick up some of these differences. However, if we were not able to control fully for speed/quality differences by means of technology dummies, the effect of price on demand would be understated and price elasticities would be underestimated. Because of price endogeneity there is a positive correlation between the price and unobserved speed/quality or unobserved demand shocks (see Nevo (2000)). Our results are therefore conservative with respect to market definition.
} 
Table 4: Technology-level own/cross price elasticities for mixed logit

\begin{tabular}{|l||c|c|c|c|c|c|c|}
\hline \hline Country-level & & & & & & & \\
\hline \hline & cable modem & DSL & fibre & WiFi & mobile & Obs & $\%$ \\
\hline \hline cable modem & -3.06 & 0.13 & 0.29 & 0.16 & 0.08 & 346 & $5.4 \%$ \\
\hline DSL & 0.66 & -3.02 & 0.66 & 1.50 & 0.47 & 1,600 & $24.8 \%$ \\
\hline fibre & 1.07 & 0.50 & -2.75 & 0.80 & 0.27 & 1,092 & $16.9 \%$ \\
\hline WiFi & 0.07 & 0.12 & 0.08 & -4.94 & 0.06 & 165 & $2.6 \%$ \\
\hline mobile & 0.17 & 0.20 & 0.16 & 0.29 & -1.42 & 923 & $14.3 \%$ \\
\hline No internet & & & & & & 2,320 & $36.0 \%$ \\
\hline & & & & & & 6,446 & $100.0 \%$ \\
\hline Municipality-level & & & & & & & \\
\hline \hline & cable modem & DSL & fibre & WiFi & mobile & Obs & $\%$ \\
\hline cable modem & -4.01 & 0.59 & 0.57 & 1.36 & 0.36 & 346 & $5.4 \%$ \\
\hline DSL & 0.94 & -4.18 & 0.96 & 3.97 & 0.86 & 1,600 & $24.8 \%$ \\
\hline fibre & 1.26 & 1.60 & -3.04 & 2.37 & 0.61 & 1,092 & $16.9 \%$ \\
\hline WiFi & 0.14 & 0.27 & 0.15 & -7.49 & 0.11 & 165 & $2.6 \%$ \\
\hline mobile & 0.22 & 0.26 & 0.23 & 0.31 & -1.48 & 923 & $14.3 \%$ \\
\hline No internet & & & & & & 2,320 & $36.0 \%$ \\
\hline & & & & & & 6,446 & $100.0 \%$ \\
\hline
\end{tabular}

This table shows own- and cross- price elasticities for different technologies, based on the mixed logit estimates from Table 8 in the appendix. The top panel shows the elasticities at the level of the country. The bottom panel shows the elasticities at the level of the municipalities, averaged across all municipalities. 
own-price elasticities range from -4.93 for $\mathrm{WiFi}$, to -3.06 for cable modem, -2.75 for fibre and -1.42 for mobile.

It is also interesting to consider the cross-price elasticities, which measure the extent to which households substitute to other technologies after a price increase. We focus on the DSL row in Table 4 which shows the percentage increase in demand for other technologies when the price of DSL increases by $1 \%$, holding everything else constant. This reveals that DSL consumers are most likely to substitute to WiFi (cross-price elasticity of 1.50). Furthermore, DSL consumers are more or less equally likely to substitute to fibre, cable and mobile. The fact that the substitution between DSL-mobile is comparable to the substitution between DSL-fibre and DSL-cable may seem surprising at first because fibre and cable are also a fixed broadband technologies. However, it can be explained by the fact that the substitution effects are the combined result of intrinsically correlated preferences and different geographic availabilities. On the one hand, households may have correlated preferences for mobile versus fixed technologies (as follows from the significant random coefficient on the mobile dummy). But on the other hand, the geographic availability overlaps much more strongly between DSL and mobile than between DSL and fibre or DSL and cable. This is evident from Table 5, which shows that among the 5,836 households that have access to DSL according to VUS data, 5,475 also have access to mobile, compared with only 3,749 that also have access to fibre, or only 2,266 that also have access to cable. ${ }^{42,43}$

We now discuss the price elasticities for groups of technologies, instead of the individual technologies. The estimates are shown in Table 6, calculated using formula (7) given in the previous section. As a reference point, the first column shows the price elasticity for DSL only

\footnotetext{
${ }^{42}$ The estimated cross-price elasticities in the simple multinomial logit model without random coefficients are also consistent with this explanation. In this model we found that the cross-price elasticity of DSL with respect to mobile is even larger at 1.14 , compared with only 0.57 for fibre. This result is entirely due to the stronger geographic overlap between DSL and mobile than between DSL and fibre because the multinomial logit does not account for unobserved correlation of preferences.

${ }^{43}$ Taking the numbers from the diagonal in Table 5 and dividing them by the sample size of 6,446 gives technology coverage information for our data: $35 \%$ for cable modem, $90 \%$ for DSL, $59 \%$ for fibre, $82 \%$ for WiFi and $92 \%$ for mobile. These numbers appear to be higher than statistics reported by OECD for 2008-2009: 24\% for cable modem, $78 \%$ for DSL, $20 \%$ for fibre and $81 \%$ for mobile. A greater coverage may lead to overestimated price elasticities but also according to OECD statistics DSL and mobile are technologies with the highest coverage, which has impact on substitution between them.
} 
Table 5: Overlaps in coverage

\begin{tabular}{|l||c|c|c|c|c|}
\hline \hline & cable modem & DSL & fibre & WiFi & mobile \\
\hline \hline cable modem & 2,274 & 2,266 & 2,251 & 2,163 & 2,274 \\
\hline DSL & 2,266 & 5,836 & 3,749 & 4,798 & 5,475 \\
\hline fibre & 2,251 & 3,749 & 3,801 & 3,347 & 3,748 \\
\hline $\mathrm{WiFi}$ & 2,163 & 4,798 & 3,347 & 5,267 & 4,954 \\
\hline mobile & 2,274 & 5,475 & 3,748 & 4,954 & 5,971 \\
\hline \hline
\end{tabular}

The diagonal shows the number of households for which given technology was available. Off-diagonal numbers show households for which a pair of technologies was available. The maximum availability is given by the sample size of 6,446 .

(identical to the relevant number in Table 4). The second column shows the price elasticity of demand for all fixed broadband technologies: this is the percentage effect of a joint $1 \%$ price increase of DSL, cable modem, fibre and WiFi on the total demand of these technologies. Finally, the third column shows the price elasticity of demand for all broadband technologies, i.e., also including mobile broadband.

The price elasticity of demand for fixed broadband technologies (second column) is equal to -1.98, which is lower (in absolute value) than the price elasticity at the level of DSL only (-3.02). This is because substitution possibilities are more limited for households if all fixed technologies raised their prices jointly. Finally, the price elasticity of all broadband technologies including mobile (third column) is equal to $-1.51 .^{44}$

\subsection{Price elasticities at the municipality level}

We also consider elasticities at the municipality level instead of country level. These elasticities are relevant if firms can follow local pricing policies. Since for many municipalities in the survey we have only 1 respondent, we cannot analyze all municipalities separately. We will therefore

\footnotetext{
${ }^{44}$ We have used 100 random draws from the covariance matrix of the parameter estimates to bootstrap confidence intervals for our elasticities. The confidence intervals are very narrow and our conclusions with respect to market definition are valid for the range of values between the mean minus/plus standard error. For example, the country-level elasticities (first row in Table 6) have a standard error of 0.050 for DSL, 0.045 for fixed broadband, and 0.037 for total broadband.
} 
Table 6: Group-level own price elasticities: DSL, fixed, and all broadband for mixed logit

\begin{tabular}{|l||r|r|c||l|}
\hline \hline & DSL & fixed & broadband & population \\
\hline \hline Country-level & -3.02 & -1.98 & -1.51 & $4,359,989$ \\
\hline Municipality-level & -4.18 & -3.50 & -1.93 & $4,359,989$ \\
\hline Municipality-level $>20$ respondents & -3.90 & -2.26 & -1.68 & $2,257,242$ \\
\hline Municipality-level $\leq 20$ respondents & -4.19 & -3.56 & -1.94 & $2,102,747$ \\
\hline \hline
\end{tabular}

This table shows the group-level own price elasticities for mixed logit estimates in Table 8 in the appendix for various alternative definitions of group: (i) group=DSL, which is simply the technology-level elasticity reported earlier in Table 4; (ii) group=fixed, which is DSL + cable modem + fibre + WiFi, (iii) group=all broadband, which is fixed + mobile. Municipality-level elasticities are averages over all municipalities, averages over municipalities with $>20$ respondents, and averages over municipalities with $\leq 20$ respondents.

summarize our results by clustering the municipalities into two groups: (i) municipalities with $>20$ respondents; and (ii) municipalities with $\leq 20$ respondents, for which we only compute an average across municipalities.

The bottom matrix in Table 4 presents mean own-price and cross-price elasticities at the municipality level for the five individual technologies. The mean price elasticities range from -7.49 for WiFi, -4.18 for DSL, -4.01 for cable modem, to -3.04 for fibre and -1.48 for mobile. Note that the mean municipality-level elasticities increase somewhat (in absolute terms) relative to the country-level elasticities. ${ }^{45}$

Similarly, the bottom part of Table 6 reports the own-price elasticities at the municipality level, for groups of technologies: DSL only, all fixed broadband, and all broadband. The mean elasticity across municipalities is -4.18 for DSL only, -3.50 for all fixed broadband, and -1.93 for all broadband (fixed + mobile). The mean elasticities for the subset of municipalities with at least 20 respondents are lower. Table 9 in the appendix provides more detailed information on the elasticities for the full set of 50 municipalities with at least 20 respondents. These estimates confirm that the price elasticity of fixed broadband is high (in absolute value): in all these municipalities the demand for fixed broadband is elastic, and in 45 out of 50 municipalities the

\footnotetext{
${ }^{45}$ We have also calculated average municipality-level elasticities weighted by the population or the number of survey respondents per municipality, which are generally higher in absolute terms than non-weighted average elasticities.
} 
elasticity is even larger than 1.50 .

\subsection{Sensitivity analysis}

To assess the robustness of our conclusions, we performed a sensitivity analysis for a few alternative specifications including: (i) multinomial logit specification (shown in Table 8 in the appendix), (ii) specification assuming homogeneous price coefficients (no household interaction variables with price); (iii) specification including TV bundle dummy variable; (iv) specification including secondary Internet connection dummy variable; and (v) specification based on all households (instead of only households that subscribed after 2006). The results (not shown in the paper) are robust for specifications (i)-(iv), with fixed broadband elasticities ranging from -1.87 to -2.09 . The lowest number of -1.87 is obtained for specification (iv), which included TV bundle dummy variable. Finally, specification (v) results in a fixed broadband price elasticity of -1.67. These early adopters may be less price sensitive, or they may have based their adoption decision on a different tariff than the current one used in the analysis. ${ }^{46}$ In any case, as discussed earlier, it is reasonable to limit the sample to households that adopted broadband after 2006, because the tariffs in the data are a better proxy for the tariffs at the time when the households made their technology decision.

We also estimated an alternative model in which the share of non-Internet households and hence the size of market is greater. The number of households which choose to have no Internet connection at all is determined on the basis of survey question, in which households were asked about plans to set up an Internet connection in the next 12 months. Those households which answered 'definitely yes' or 'rather yes' were considered to be 'no Internet' households in our

\footnotetext{
${ }^{46}$ Broadband subscribers may be locked-in by contractual restrictions. Unfortunately, we cannot take the dynamic aspects of decision-making into account because we have only a single period of data and no information on the commitment period. However, our sensitivity analysis suggests a direction in which price elasticities may change if at least contractual restrictions were considered. Limiting sample to households which adopted broadband after 2006 is equivalent to assuming that consumers who subscribed before 2006 are locked-in. Therefore, they cannot make a new subscription decision and are out of the market, which reduces the overall number of decision makers. This results in a higher share of outside option, lower technology shares and therefore based on the logit elasticity formulas, should lead to higher own price elasticities. Indeed, estimating a model on the limited sample yields higher price elasticities than on the sample which is not limited by the subscription date. It would be interesting in future research to consider the dynamics in more detail, in particular by considering the role of contractual restrictions such as the number of months a household is under contract.
} 
base model. In the alternative model, we also include as 'no Internet' households those which answered 'rather not', assuming that they may be part of the market if broadband price were sufficiently low. Households which answered 'definitely not' were dropped from the estimation as before. In this case sample size increases to $7,282(3,156+4,126)$ when only households who started their current Internet connection after 2006 are considered and to 8, 736(3, $156+5,580)$ when the sample is unrestricted by starting date. The resulting estimates of elasticities increase substantially. The country-level fixed broadband elasticity increases to -2.37 and the countrylevel broadband elasticity increases to $-1,87$ in the first case. When the sample used in the estimation is unrestricted by the starting date, the country-level elasticity for fixed broadband decreases to -1.82 and the country-level broadband elasticity decreases to -1.46 .

Due to the fact that we collected tariff data for 47 main Internet providers and most of the WiFi providers are very small, the share of WiFi users is under-represented. We could not match survey data with tariffs data for small WiFi providers. We assess the sensitivity of results with respect to the share of $\mathrm{WiFi}$ households in the sample by using alternative price for selected WiFi technology in cases when tariff data is missing. Households for which we lack tariff data are assigned a tariff offered by a different WiFi operator than the one selected, where the coverage of selected WiFi operators is also extended respectively. The market share of WiFi users increases to $8 \%$ from $3 \%$ in our base model specification. The country-level fixed broadband elasticity in this version of the model decreases slightly to -1.92 and the country-level broadband elasticity remains unchanged at -1.49 .

\subsection{Implications for market definition}

What are the implications from these estimates for the definition of the relevant market for broadband? Should the relevant market be defined at the level of the individual broadband access technologies, at the level of all fixed broadband, or at the level of all broadband (fixed + mobile)? An answer to these questions is important for regulation and competition policy, not just in Slovakia but also in other CEE countries. ${ }^{47}$ We can address these questions in two ways:

\footnotetext{
${ }^{47}$ Market definition has been criticized over the past decades, especially in the context of merger analysis where alternative approaches have been proposed, such as UPP-tests and merger simulation. These approaches can be useful to predict the likely price increases from mergers more directly (also based on price elasticities and diversion ratio). For example, even with a broad market definition, it is possible that mergers result in significant price increases. Nevertheless, market definition continues to be important in various areas of competition policy,
} 
by comparing our elasticity estimates to other literature, and by conducting a SSNIP-test using critical loss analysis.

First, it is instructive to compare our estimated price elasticities with other estimates obtained in the literature. The most relevant studies are Cardona et al. (2009) and Srinuan et al. (2012), which both estimate discrete choice models comparable to our approach. The first paper accounts for unobserved heterogeneity using nested logit model, whereas our mixed logit model includes random coefficients for mobile versus fixed technologies and for the price variable. Both studies are based on relatively recent data when broadband penetration reached high levels. The main difference between these studies and our own relates to the country of analysis. They analyze broadband demand in Western European countries (Austria and Sweden), which have copper networks of higher quality. In contrast, we study a Central and Eastern European country where investments in the copper network have been limited due to historical reasons, which made DSL comparatively less important and encouraged investments in alternative platforms including mobile broadband.

Both studies only report elasticities at the level of the individual technologies. For Austria, Cardona et al. (2009) find price elasticity of demand for DSL of -2.55. For Sweden, Srinuan et al. (2012) obtain elasticity of demand for DSL of -2.72 (in areas where all technologies are available). Both studies conclude that mobile is a strong substitute for fixed broadband. Our own estimates point to more elastic demand for DSL of -3.02 at the country-level, which is even larger at the municipality-level. Furthermore, we find that the price elasticity of demand for all fixed broadband technologies (when they all jointly raise their prices) remains very elastic at -1.98. Thus, there is a strong indication that mobile broadband forms an important substitute to fixed technologies.

Second, we can use these elasticities as part of a hypothetical monopoly test or SSNIP-test for defining the relevant market. This test defines a group of products as the relevant market if a joint price increase of $5-10 \%$ raises profits for that group. If it does not, this means that there is sufficiently strong substitution, so that the market should be defined more broadly. Implementing the market definition test requires information about price elasticities to measure substitution out of the candidate relevant market. But there is also needed information on percentage profit margins, i.e., price over marginal cost, to measure the value of the sales losses especially in the context of telecommunications in Europe. 
after the price increase. Critical loss analysis formalizes how to incorporate elasticities and profit margins in a SSNIP test. More specifically, it computes the critical elasticity above which the market should be defined more broadly than the candidate relevant market (see Harris and Simons (1989)). Having estimates of the price elasticity, we can equivalently compute the critical profit margin above which the relevant market should be broader than the candidate relevant market. This is given by the condition $m>1 / \varepsilon-t$, where $m$ is the percentage profit margin over marginal cost (the Lerner index); $\varepsilon$ is the elasticity at the level of the candidate relevant market (i.e., DSL + other fixed broadband technologies); and $t$ is the percent price increase of the SSNIP-test, usually $t=10 \%$. For the estimated price elasticity of fixed broadband demand at the country level of -1.98 , the relevant market should be broader than fixed broadband, if the percentage profit margin is $40.5 \%$ or higher. ${ }^{48}$

Information on profit margins is difficult to obtain, because it requires information on marginal costs. Cardona et al. (2009) and the Austrian regulator RTR use confidential information to obtain an indication of profit margins. They distinguish between various cost categories (access, backhaul and other), and classify these components in either variable or fixed. They suggest that profit margins over marginal cost are about $60 \%$ or higher. ${ }^{49}$ Information from other sources also indicates that profit margins are high, but presumably somewhat lower than suggested by Cardona et al. (2009). For example, WIK (2010) provides cost estimates in the context of new fiber networks. WIK calculates certain cost elements as a share of total expenses. Considering the share of passive network costs, profit margins over marginal costs may rather be around 50\%. This would also be consistent with the estimated price elasticities of demand in Table 4, together with multi-product price setting behavior. In sum, these sources suggest that margins are indeed higher than $40.5 \% .^{50}$ This implies that the relevant market is broader than

\footnotetext{
${ }^{48}$ If providers set prices as single-product firms, the margins can be calculated using the simple Lerner index formula, i.e., as the inverse of the own price elasticities reported in Table 4 . This would give a weighted average margin for fixed broadband technologies of $33 \%(1 / 3.06=33 \%$ for cable; $1 / 3.02=33 \%$ for DSL; $1 / 2.75=36 \%$ for fibre; and $1 / 4.94=20.2 \%$ for $\mathrm{WiFi}$ ). However, this single-product Lerner index only provides a lower bound, since the main firms provide multiple technologies: ST offers both DSL and Fibre, Orange offers Fibre and Mobile, Slovanet offers DSL, Fibre and WiFi. Given the sizeable cross-price elasticities in Table 4, the multi-product Lerner index would be considerably larger, in the range of $40 \%-50 \%$.

${ }^{49}$ See "Abgrenzung des Marktes für breitbandigen Zugang auf Vorleistungsebene," Rundfunk und Telekom Regulierungs-GmbH, Dezember 2009.

${ }^{50}$ While this is not immediately relevant for our purposes, an upper bound on the price-cost margin may be derived under the assumption that all broadband suppliers would be perfectly colluding by maximizing joint
} 
fixed broadband and should also include mobile broadband. ${ }^{51}$

\section{Conclusions}

In this paper we use data from a rich survey of 6,446 households in Slovakia to estimate price elasticities of demand for Internet access. We estimate a mixed logit model, in which households choose between different broadband technologies: DSL, cable modem, fibre, WiFi and mobile. The model accounts for both observed household determinants and unobserved heterogeneity. We find that some household characteristics significantly influence price sensitivity and technology choices. There is also unobserved heterogeneity with respect to households' price sensitivity and valuation of mobile broadband.

The analysis enables us to estimate flexible aggregate substitution patterns and calculate price elasticities of demand at various levels: DSL only, fixed broadband and all broadband (including mobile). We calculate these elasticities at two geographic aggregation levels: for individual municipalities and for the country as a whole. Municipality-level elasticities are more relevant if companies can follow a local pricing policy, whereas country-level elasticities are more relevant if companies can only follow a national pricing policy.

We find that the demand for Internet access is highly price sensitive. The country-level price elasticity of demand for DSL is -3.02 , which falls in the middle of the range of elasticities for the other technologies. Municipality-level price elasticities are on average even higher in absolute terms. Furthermore, the price elasticity of demand at the level of all fixed broadband technologies (DSL+cable modem+fibre+WiFi) is equal to -1.98 at the country-level, and -3.50 on average at the municipality-level. We perform an extensive sensitivity analysis and our results remain robust with respect to various alternative assumptions.

We use these elasticities to compute the critical profit margin above which the relevant market should be broader than the candidate relevant market, which is given by the condition $m>1 / \varepsilon-t$, where $m$ is the percentage profit margin over marginal cost (the Lerner index); $\varepsilon$

profits. Given our estimated elasticity of demand for total broadband of -1.51, this would imply the maximum profit margin is $1 / 1.51=0.66$. In practice, it is therefore likely that the profit margin is considerably lower.

${ }^{51}$ In principle, the conclusion of a broad market may be subject to a Cellophane Fallacy, i.e., products may be elastic at the going prices, but not at competitive prices. This issue does not however appear to be a relevant concern here. First, there are large fixed investment costs that need to be recovered from the price-cost margins. Second, there are many active firms, and there is no evidence that these firms are colluding. 
is the elasticity at the level of the candidate relevant market (i.e., DSL + other fixed broadband technologies); and $t$ is the percent price increase of the SSNIP-test, usually $t=10 \%$. For the estimated price elasticity of fixed broadband demand at the country level of -1.98 , the relevant market should be broader than fixed broadband if the percentage profit margin is $40.5 \%$ or higher, which appears reasonable in this market. The evidence from other studies suggests that margins in broadband market are substantially higher than $40.5 \%$, which implies that mobile broadband should be included in the relevant antitrust market of fixed broadband.

Our findings have important implications for regulation and competition policy in countries with a similar structure of broadband market to Slovakia, and especially for the other CEE countries. As discussed before, the CEE countries inherited from the socialism era poor fixed-line infrastructure. When entering the EU, the lack of a reliable copper network promoted investment in alternative platforms for broadband access. As a result, there is a strong market share of mobile broadband technologies in these countries. It seems therefore unwise to automatically presume that broadband markets in the CEE countries should be delineated in the same way as in their Western counterparts where fixed-line networks have historically been much stronger. 


\section{Bibliography}

Ben-Akiva, M., McFadden, D.L. and K.E. Train, 1987. "The Demand for Local Telephone Service: A Fully Discrete Model of Residential Calling Patterns and Service Choices," Rand Journal of Economics, 18(1), pp.109-23.

Cardona M., Schwarz A., Yurtoglu, B.B. and Ch. Zulehner, 2009. "Demand Estimation and Market Definition for Broadband Internet Services," Journal of Regulatory Economics, $35(1)$, pp.70-95.

Crandall, R.W., Sidak, J.G. and H.J. Singer, 2002. "The empirical case against asymmetric regulation of broadband Internet access," Berkeley Law and Technology Journal, 17(1), pp.953-987.

Crooke, P., L. Froeb, S. Tschantz and G. Werden, 1999. "The Effects of Assumed Demand Form on Simulated Post-Merger Equilibria," Review of Industrial Organization, 15(3), pp.205-217.

Durand, B. and E. Pesaresi, 2007. "Empirical estimation of a discrete choice model for filler calcium carbonates in the paper industry," Merger Control.

Dutz, M., Orszag, J., and R. Willig, 2009. "The Substantial Consumer Benefits of Broadband Connectivity for U.S. Households, ” Mimeo.

Froeb, L. and S. Tschantz, and G. Werden, 2005, Pass-Through Rates and the Price Effects of Mergers, International Journal of Industrial Organization, 23, pp.703-715.

Grzybowski, L. and P. Pereira, 2007. "Simulation of Merger in mobile Telephony in Portugal," Review of Industrial Organization, 31(3), pp.205-220.

Grzybowski, L. and P. Pereira, 2011. "Subscription Choices and Switching Costs in mobile Telephony," Review of Industrial Organization, 38, pp.23-42.

Hausman, J.A., Sidak, J.G. and H.J., Singer, 2001. "cable Modems and DSL: Broadband Internet Access for Residential Customers" American Economic Review, 91(2), pp.302-307.

Harris, B. and J. Simons, 1989. "Focusing Market Definition: How Much Substitution in Necessary?," Research in Law and Economics, 12. 
Ida, T. and T. Kuroda, 2006. "Discrete choice analysis of demand for broadband in Japan," Journal of Regulatory Economics, 29(1), 5-22.

Ivaldi, M. and S. Lorincz, 2011. "Full Equilibrium Relevant Market Test: Application to Computer Servers," Review of Law and Economics, 7(1), pp.31-73.

Ivaldi, M. and F. Verboven, 2005. "Quantifying the effects from horizontal mergers in European competition policy," International Journal of Industrial Organization, 23, pp.669-691.

Lee, J., Kim, Y., Lee, J.D. and Y. Park, 2006. "Estimating the Extent of Potential Competition in the Korean mobile Telecommunications Market: Switching Costs and Number Portability," International Journal of Industrial Organization, 24, pp.107-124.

Nevo, A. 2000. "Mergers with differentiated products: The case of the ready-to-eat cereal industry," Rand Journal of Economics, 31, pp.395-421.

Pereira, P. and T. Ribeiro, 2011. "The impact on broadband access to the Internet of the dual ownership of telephone and cable networks," International Journal of Industrial Organization, 29, pp.283-293.

Rappoport, P., Kridel, D., Taylor, L., Duffy-Deno, K. and J. Allemen, 2003. "Residential demand for access to the Internet," Chapter 5. In G. Madden (Ed.), International Handbook of Telecommunications Economics, (Vol.II). Cheltenham, UK: Edward Elgar.

Srinuan, P., Srinuan, C. and E., Bohlin, 2012, Fixed and Mobile Broadband Substitution in Sweden," Telecommunications Policy, 36, pp. 237-251.

Train, K., 2003. "Discrete Choice Methods with Simulation," Cambridge University Press, Cambridge. 
Appendix 1 
Table 7: Sample statistics

\begin{tabular}{|c|c|c|c|c|c|c|}
\hline & "Variable & Obs Mean & Std. Dev. & Min & Max & $\overline{\mathrm{N}}$ \\
\hline \multirow[t]{6}{*}{ cable modem } & Age & 39.34 & 12.57 & 18 & 74 & 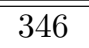 \\
\hline & Male dummy & 0.51 & 0.50 & 0 & 1 & 346 \\
\hline & Household size & 2.85 & 1.12 & 1 & 5 & 346 \\
\hline & Income & 1.35 & 1.11 & 0.3 & 5 & 346 \\
\hline & Apartment dummy & 0.91 & 0.29 & 0 & 1 & 346 \\
\hline & Having fixed-line dummy & 0.39 & 0.49 & 0 & 1 & 346 \\
\hline \multirow{8}{*}{ DSL } & Had Internet before & 0.42 & 0.49 & 0 & 1 & 346 \\
\hline & Age & 39.62 & 12.72 & 18 & 78 & 1,600 \\
\hline & Male dummy & 0.51 & 0.50 & 0 & 1 & 1,600 \\
\hline & Household size & 3.61 & 1.16 & 1 & 5 & 1,600 \\
\hline & Income & 1.12 & 0.86 & 0.3 & 5 & 1,600 \\
\hline & Apartment dummy & 0.36 & 0.48 & 0 & 1 & 1,600 \\
\hline & Having fixed-line dummy & 0.53 & 0.50 & 0 & 1 & 1,600 \\
\hline & Had Internet before & 0.23 & 0.42 & 0 & 1 & 1,600 \\
\hline \multirow[t]{7}{*}{ fibre } & Age & 39.48 & 12.44 & 18 & 78 & 1,092 \\
\hline & Male dummy & 0.53 & 0.50 & 0 & 1 & 1,092 \\
\hline & Household size & 3.28 & 1.18 & 1 & 5 & 1,092 \\
\hline & Income & 1.22 & 0.98 & 0.3 & 5 & 1,092 \\
\hline & Apartment dummy & 0.78 & 0.41 & 0 & 1 & 1,092 \\
\hline & Having fixed-line dummy & 0.34 & 0.47 & 0 & 1 & 1,092 \\
\hline & Had Internet before & 0.36 & 0.48 & 0 & 1 & 1,092 \\
\hline \multirow[t]{7}{*}{$\overline{\mathrm{WiFi}}$} & Age & 36.93 & 10.74 & 18 & 69 & 165 \\
\hline & Male dummy & 0.55 & 0.50 & 0 & 1 & 165 \\
\hline & Household size & 3.82 & 1.09 & 1 & 5 & 165 \\
\hline & Income & 1.22 & 1.02 & 0.3 & 5 & 165 \\
\hline & Apartment dummy & 0.31 & 0.46 & 0 & 1 & 165 \\
\hline & Having fixed-line dummy & 0.33 & 0.47 & 0 & 1 & 165 \\
\hline & Had Internet before & 0.30 & 0.46 & 0 & 1 & 165 \\
\hline \multirow[t]{7}{*}{ mobile } & Age & 38.63 & 12.37 & 18 & 73 & 9923 \\
\hline & Male dummy & 0.46 & 0.50 & 0 & 1 & 923 \\
\hline & Household size & 3.41 & 1.22 & 1 & 5 & 923 \\
\hline & Income & 1.12 & 0.88 & 0.3 & 5 & 923 \\
\hline & Apartment dummy & 0.43 & 0.50 & 0 & 1 & 923 \\
\hline & Having fixed-line dummy & 0.29 & 0.46 & 0 & 1 & 923 \\
\hline & Had Internet before & 0.25 & 0.44 & 0 & 1 & 923 \\
\hline \multirow[t]{7}{*}{ No internet } & Age & 40.71 & 13.64 & 18 & 79 & 2,320 \\
\hline & Male dummy & 0.49 & 0.50 & 0 & 1 & 2,320 \\
\hline & Household size & 3.08 & 1.28 & 1 & 5 & 2,320 \\
\hline & Income & 0.79 & 0.53 & 0.3 & 5 & 2,320 \\
\hline & Apartment dummy & 0.48 & 0.50 & 0 & 1 & 2,320 \\
\hline & Having fixed-line dummy & 0.28 & 0.45 & 0 & 1 & 2,320 \\
\hline & Had Internet before & 0.00 & 0.00 & 0 & 0 & 2,320 \\
\hline
\end{tabular}




\begin{tabular}{|c|c|c|c|c|c|c|c|c|c|c|c|c|c|c|c|c|c|}
\hline & 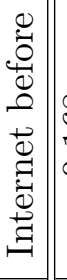 & 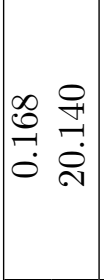 & 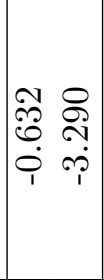 & 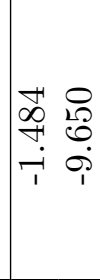 & 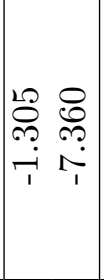 & 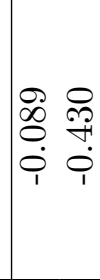 & & & 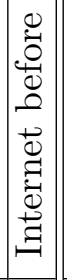 & 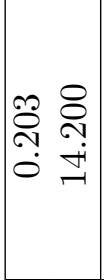 & 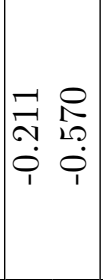 & 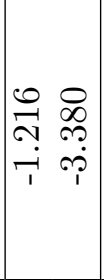 & 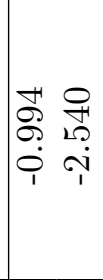 & 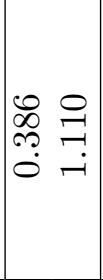 & & & 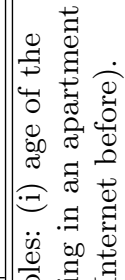 \\
\hline & 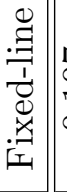 & $\mid$\begin{tabular}{cc}
1 & 8 \\
0 & 8 \\
\hdashline & 0 \\
0 & 0 \\
0 & 0
\end{tabular} & 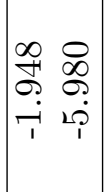 & $\begin{array}{ll}10 & 8 \\
0 & \infty \\
0 & 0 \\
-1 & 0 \\
& 0\end{array}$ & 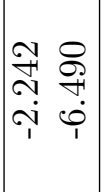 & 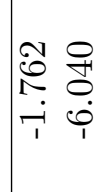 & 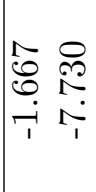 & & 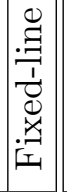 & 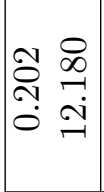 & 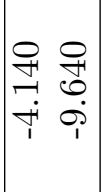 & 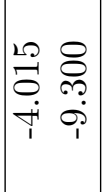 & 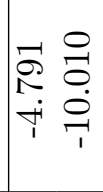 & 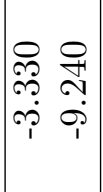 & 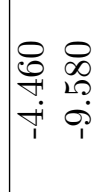 & & 侟 \\
\hline & 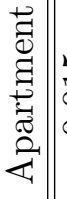 & 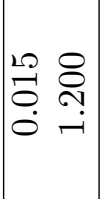 & 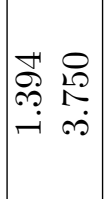 & $\begin{array}{ll}\vec{D} & 8 \\
0 & 0 \\
0 & \ddots \\
0 & 9\end{array}$ & 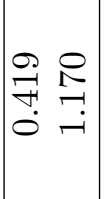 & 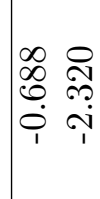 & 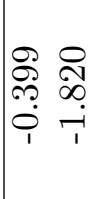 & & 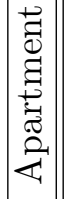 & 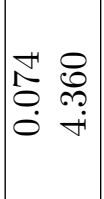 & \begin{tabular}{cc}
0 & 0 \\
$\infty$ & 1 \\
\hdashline & 0 \\
\hdashline & 0 \\
0 & 0
\end{tabular} \mid & 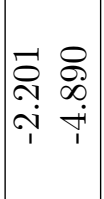 & 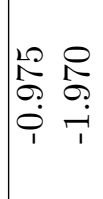 & 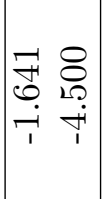 & $\begin{array}{ll}0 & 8 \\
0 & 0 \\
0 & 0 \\
i & 1 \\
1 & 1\end{array}$ & & 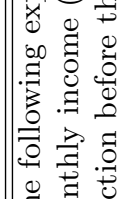 \\
\hline & 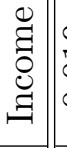 & $\left|\begin{array}{cc}0 & 0 \\
0 & \infty \\
0 & 0 \\
0 & i \\
0 & i\end{array}\right|$ & 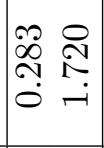 & $\begin{array}{ll}10 & 0 \\
\exists & \stackrel{1}{1} \\
0 & 0\end{array}$ & 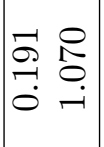 & 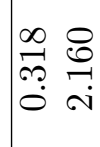 & 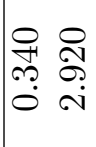 & & 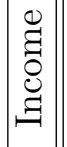 & 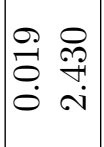 & 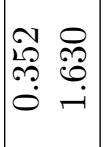 & 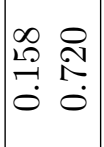 & 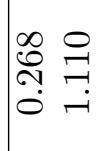 & $\left|\begin{array}{ll}2 & 8 \\
2 & 0 \\
\hdashline & 0 \\
\hdashline & -1 \\
0 & 0\end{array}\right|$ & 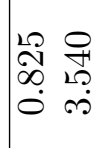 & & $\int_{3}^{0}$ \\
\hline & 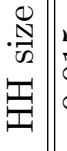 & 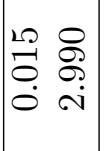 & 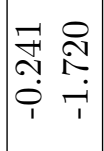 & \begin{tabular}{ll}
$\vec{m}$ & 8 \\
\hdashline & 0 \\
\hdashline & 0 \\
1 & 0 \\
1 & 0
\end{tabular} & $\left|\begin{array}{ll}0 & 0 \\
0 & 0 \\
0 & 0 \\
0 & 0 \\
1 & 0 \\
1\end{array}\right|$ & 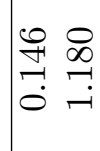 & $\begin{array}{ll}0 & 0 \\
2 & 8 \\
0 & 8 \\
0 & 0 \\
0 & 0 \\
1 & 1\end{array}$ & & 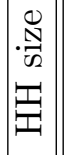 & 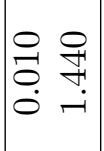 & $\mid \begin{array}{ll}0 & 0 \\
0 & 0 \\
0 & 0 \\
0 & 0 \\
1 & 0 \\
1 & 1\end{array}$ & 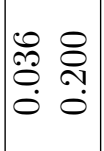 & 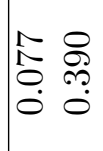 & $\left|\begin{array}{ll}0 & R \\
N & R \\
& 0 \\
& \infty \\
0 & -i\end{array}\right|$ & 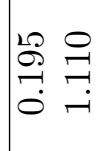 & & 㻤 \\
\hline & $\left.\frac{0}{\frac{0}{\sigma}}\right)$ & 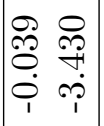 & 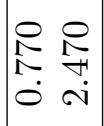 & $\begin{array}{ll}\vec{b} & 0 \\
\infty & \\
\infty & \infty \\
0 & \stackrel{v}{0}\end{array}$ & 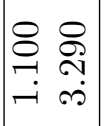 & 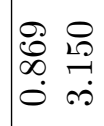 & 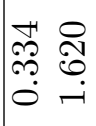 & & $\frac{\stackrel{0}{\pi}}{\stackrel{\pi}{\Sigma}}$ & 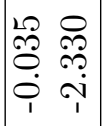 & 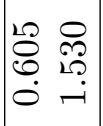 & 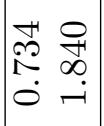 & 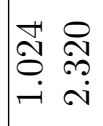 & 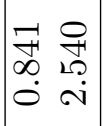 & 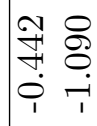 & & $\underset{凶}{\breve{~}}$ \\
\hline & \begin{tabular}{l||}
8 \\
$\&$ \\
$\&$
\end{tabular} & 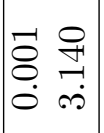 & 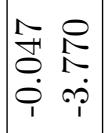 & 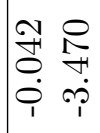 & 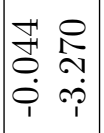 & 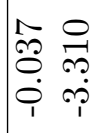 & 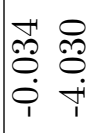 & & $\mid$\begin{tabular}{c|}
8 \\
80 \\
4
\end{tabular} & 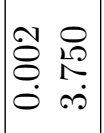 & 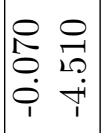 & 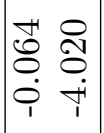 & $\begin{array}{ll}0 & 0 \\
0 & 0 \\
0 & 0 \\
0 & \stackrel{+}{+}\end{array}$ & 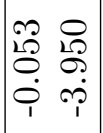 & $\begin{array}{ll}10 & 8 \\
0 & 8 \\
0 & 8 \\
1 & 9\end{array}$ & & 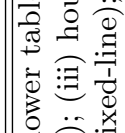 \\
\hline$\underset{\not}{\not}$ & 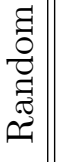 & & & & & & & & 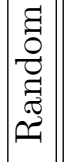 & 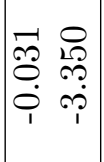 & & & & & 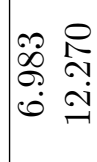 & $\mid \begin{array}{ll}\overrightarrow{1} & 0 \\
0 & 0 \\
0 & 0 \\
0 & 0\end{array}$ & $\mid \begin{array}{l}\vec{Z} \\
\tilde{\tilde{\sigma}} \\
\tilde{\sigma}\end{array}$ \\
\hline \begin{tabular}{|c|}
2 \\
20 \\
0 \\
0 \\
1 \\
1 \\
\end{tabular} & 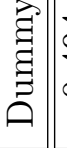 & 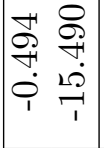 & $\begin{array}{ll}\exists & 8 \\
0 & 0 \\
0 & 0 \\
\infty & 0\end{array}$ & 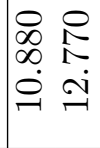 & 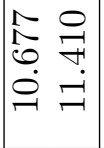 & $\begin{array}{ll}0 & 8 \\
8 & 8 \\
0 & 0 \\
15 & 0\end{array}$ & 点 & $\mid \begin{array}{c}\infty \\
\stackrel{N}{4} \\
20 \\
i \\
\end{array}$ & 窵 & $\mid \begin{array}{cc}\infty & 0 \\
0 & 0 \\
0 & 0 \\
0 & 0 \\
0 & 1 \\
1 & \stackrel{1}{1} \\
1 & 1\end{array}$ & 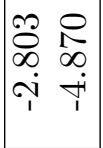 & & 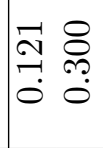 & 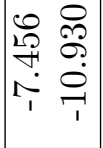 & 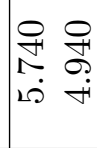 & 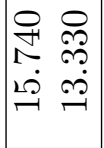 & $\mid \begin{array}{ll}0 \\
0 \\
0\end{array}$ \\
\hline 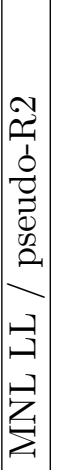 & & 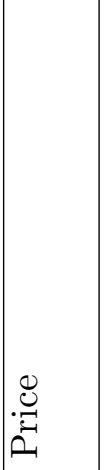 & $\frac{0}{\frac{0}{0}}$ & $\overrightarrow{\tilde{\Omega}}$ & $\mid$ & 容 & 党 & 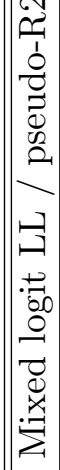 & & 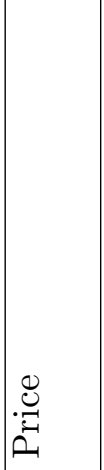 & $\frac{0}{\pi}$ & $\overrightarrow{\tilde{\Omega}}$ & $\frac{0}{\stackrel{0}{|c|}}$ & $\mid \overrightarrow{|c|}$ & $\stackrel{0}{\stackrel{0}{7}}$ & 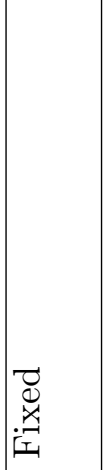 & 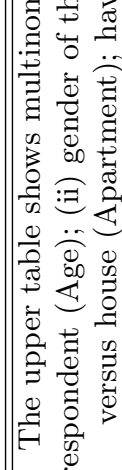 \\
\hline
\end{tabular}


Table 9: Municipality-level own-price elasticities for municipalities with $>20$ respondents

\begin{tabular}{|c|c|c|c|c|c|c|}
\hline & & mixed & & & & \\
\hline county & town & DSL & fixed & broadband & respondents & population \\
\hline Bratislava & Bratislava & \begin{tabular}{c|}
-4.19 \\
\end{tabular} & \begin{tabular}{|c|c|}
-1.64 \\
\end{tabular} & 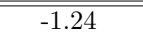 & 632 & 428,791 \\
\hline Kosice & Kosice & -4.45 & -1.67 & -1.33 & 300 & 233659 \\
\hline Banska Bystrica & Banska Bystrica & -4.76 & -2.07 & -1.56 & 157 & 80,106 \\
\hline Zilina & Zilina & -4.59 & -2.11 & -1.60 & 141 & 85,327 \\
\hline Presov & Presov & -3.16 & -1.51 & -1.17 & 123 & 91,273 \\
\hline Nitra & Nitra & -3.30 & -1.36 & -1.08 & 87 & 84,070 \\
\hline Trnava & Trnava & -4.24 & -2.15 & -1.60 & 86 & 67,726 \\
\hline Trencin & Trencin & -2.89 & -1.63 & -1.23 & 79 & 56,826 \\
\hline Poprad & Poprad & -3.08 & -1.65 & -1.26 & 71 & 54,621 \\
\hline Prievidza & Prievidza & -3.17 & -1.43 & -1.12 & 62 & 50,664 \\
\hline Martin & Martin & -4.36 & -0.32 & -0.21 & 60 & 58,433 \\
\hline Spisska Nova Ves & Spisska Nova Ves & -3.61 & -2.25 & -1.78 & 59 & 38,148 \\
\hline Zvolen & Zvolen & -2.58 & -1.84 & -1.46 & 57 & 42,531 \\
\hline Nove Zamky & Nove Zamky & -5.69 & -2.41 & -1.81 & 56 & 40,456 \\
\hline Humenne & Humenne & -3.49 & -3.06 & -2.26 & 56 & 34,854 \\
\hline Komarno & Komarno & -4.37 & -3.25 & -2.39 & 49 & 35,881 \\
\hline Bardejov & Bardejov & -3.63 & -1.77 & -1.25 & 49 & 33,426 \\
\hline Pezinok & Pezinok & -4.46 & -2.61 & -1.94 & 47 & 21,839 \\
\hline Roznava & Roznava & -3.20 & -2.97 & -2.18 & 47 & 18,959 \\
\hline Michalovce & Michalovce & -3.98 & -1.72 & -1.32 & 45 & 39,539 \\
\hline Levice & Levice & -3.82 & -1.82 & -1.42 & 42 & 35,492 \\
\hline Piestany & Piestany & -3.87 & -2.32 & -1.76 & 41 & 29,540 \\
\hline Topolcany & Topolcany & -4.48 & -2.85 & -2.18 & 41 & 28,566 \\
\hline Lucenec & Lucenec & -3.44 & -2.30 & -1.69 & 39 & 27,547 \\
\hline Banska Stiavnica & Banska Stiavnica & -5.62 & -2.86 & -2.13 & 39 & 10,547 \\
\hline Partizanske & Partizanske & -3.66 & -3.85 & -2.88 & 38 & 24,263 \\
\hline Hlohovec & Hlohovec & -3.80 & -2.36 & -1.63 & 37 & 22,424 \\
\hline Cadca & Cadca & -2.78 & -2.28 & -1.63 & 36 & 25,564 \\
\hline Vranov nad Toplou & Vranov nad Toplou & -4.09 & -2.32 & -1.67 & 36 & 23,107 \\
\hline Povazska Bystrica & Povazska Bystrica & -2.82 & -2.42 & -1.85 & 35 & 41,809 \\
\hline Ilava & Dubnica nad Vahom & -4.16 & -1.91 & -1.52 & 35 & 25,075 \\
\hline Brezno & Brezno & -4.39 & -1.89 & -1.53 & 34 & 22,019 \\
\hline Malacky & Malacky & -3.48 & -2.70 & -1.94 & 34 & 17,937 \\
\hline Liptovsky Mikulas & Liptovsky Mikulas & -3.91 & -1.95 & -1.58 & 33 & 32,687 \\
\hline Ruzomberok & Ruzomberok & -3.16 & -2.43 & -1.85 & 33 & 29,687 \\
\hline Trebisov & Trebisov & -4.69 & -1.65 & -1.29 & 31 & 23,356 \\
\hline Prievidza & Handlova & -4.00 & -3.14 & -2.26 & 30 & 17,683 \\
\hline Rimavska Sobota & Rimavska Sobota & -3.31 & -1.78 & -1.39 & 29 & 24,249 \\
\hline Banovce nad Bebravou & Banovce nad Bebravou & -3.69 & -2.42 & -1.69 & 28 & 20,453 \\
\hline Snina & Snina & -3.71 & -2.08 & -1.63 & 27 & 21,164 \\
\hline Ziar nad Hronom & Ziar nad Hronom & -6.12 & -1.88 & -1.45 & 25 & 19,567 \\
\hline Dunajska Streda & Samorin & -2.49 & -1.29 & -1.00 & 25 & 12,929 \\
\hline Nove Mesto nad Vahom & Nove Mesto nad Vahom & -2.41 & -1.66 & -1.18 & 24 & 20,370 \\
\hline Galanta & Sered & -3.52 & -2.44 & -1.83 & 24 & 16,986 \\
\hline Poprad & Svit & -3.68 & -3.69 & -2.44 & 24 & 7495 \\
\hline Senec & Senec & -2.85 & -1.51 & -1.05 & 22 & 16,019 \\
\hline Senica & Senica & -2.06 & -1.09 & -0.89 & 21 & 20,751 \\
\hline Kysucke Nove Mesto & Kysucke Nove Mesto & -4.60 & -4.60 & -3.05 & 21 & 16,367 \\
\hline Detva & Detva & -10.74 & -5.73 & -3.89 & 21 & 14,833 \\
\hline Bytca & Bytca & -2.49 & -2.20 & -1.77 & 21 & 11,627 \\
\hline
\end{tabular}

This table shows the municipality-level own-price elasticities for municipalities with at least 20 respondents, based on the multinomial logit and mixed logit estimates of Table 8. The elasticities refers to three groups: (i) group=DSL, which is simply the technology-level elasticity reported earlier in Tables 8 and 9; (ii) group=fixed, which is DSL + cable modem + fibre $+\mathrm{WiFi}$, (iii) group=all broadband, which is fixed + mobile. 